NBER WORKING PAPER SERIES

\title{
A DENIAL A DAY KEEPS THE DOCTOR AWAY
}

\author{
Abe Dunn \\ Joshua D. Gottlieb \\ Adam Shapiro \\ Daniel J. Sonnenstuhl \\ Pietro Tebaldi \\ Working Paper 29010 \\ http://www.nber.org/papers/w29010 \\ NATIONAL BUREAU OF ECONOMIC RESEARCH \\ 1050 Massachusetts Avenue \\ Cambridge, MA 02138 \\ July 2021, Revised January 2023
}

The views expressed in this article are solely those of the authors and do not necessarily reflect the views of the Bureau of Economic Analysis, the Federal Reserve Bank of San Francisco, the Board of Governors of the Federal Reserve System, or the National Bureau of Economic Research. Gottlieb and Tebaldi thank the Becker-Friedman Institute for Economics. Gottlieb also thanks the Social Sciences and Humanities Research Council of Canada for supporting this work, and acknowledges hospitality from Brown University and the Federal Reserve Bank of San Francisco. The editor and four anonymous referees provided numerous constructive comments which led to substantial revisions of the article. We are deeply indebted to Finn McLaughlin, Oscar Chan, Hyonggu Hwang, and Yiqing Zheng for exceptional research assistance, and we thank numerous seminar audiences for helpful comments. A previous draft of this article circulated under the title "The Costs of Payment Uncertainty in Healthcare Markets".

NBER working papers are circulated for discussion and comment purposes. They have not been peer-reviewed or been subject to the review by the NBER Board of Directors that accompanies official NBER publications.

(C) 2021 by Abe Dunn, Joshua D. Gottlieb, Adam Shapiro, Daniel J. Sonnenstuhl, and Pietro Tebaldi. All rights reserved. Short sections of text, not to exceed two paragraphs, may be quoted without explicit permission provided that full credit, including $\odot$ notice, is given to the source. 
A Denial a Day Keeps the Doctor Away

Abe Dunn, Joshua D. Gottlieb, Adam Shapiro, Daniel J. Sonnenstuhl, and Pietro Tebaldi

NBER Working Paper No. 29010

July 2021, Revised January 2023

JEL No. H52,H75,I11,I13,I14,I18,L14,L33,L88

\begin{abstract}
Who bears the consequences of administrative problems in healthcare? We use data on repeated interactions between a large sample of U.S. physicians and many different insurers to document the complexity of healthcare billing, and estimate its economic costs for doctors and consequences for patients. Observing the back-and-forth sequences of claim denials and resubmissions for past visits, we can estimate physicians' costs of haggling with insurers to collect payments. Combining these costs with the revenue never collected, we estimate that physicians lose $18 \%$ of Medicaid revenue to billing problems, compared with $4.7 \%$ for Medicare and $2.4 \%$ for commercial insurers. Identifying off of physician movers and practices that span state boundaries, we find that physicians respond to billing problems by refusing to accept Medicaid patients in states with more severe billing hurdles. These hurdles are quantitatively just as important as payment rates for explaining variation in physicians' willingness to treat Medicaid patients. We conclude that administrative frictions have first-order costs for doctors, patients, and equality of access to healthcare. We quantify the potential economic gains-in terms of reduced public spending or increased access to physicians - if these frictions could be reduced, and find them to be sizable.
\end{abstract}

Abe Dunn

Bureau of Economic Analysis

4600 Silver Hill Rd

Suitland, MD 20746

Abe.Dunn@bea.gov

Joshua D. Gottlieb

University of Chicago

Harris School of Public Policy

1307 E. 60th St.

Chicago, IL 60637

and NBER

jgottlieb@uchicago.edu

Adam Shapiro

Federal Reserve Bank of San Francisco

101 Market Street, MS 1130

San Francisco, CA 94105

adam.shapiro@sf.frb.org

\author{
Daniel J. Sonnenstuhl \\ University of Chicago \\ Harris School of Public Policy \\ 1307 East 60th Street \\ Chicago, IL 60637 \\ d.sonnenstuhl@uchicago.edu
}

Pietro Tebaldi

Department of Economics

Columbia University

IAB, MC 3308

New York, NY 10027

and NBER

pt2571@columbia.edu 


\section{Introduction}

Health insurance features an intricate system of contracts involving many private and public entities. Scholars and policymakers have argued that administering and implementing these contracts, which govern 13 percent of U.S. GDP, increases costs and reduces efficiency of U.S. healthcare (Cutler and Ly, 2011). ${ }^{1}$ Measuring administrative costs is inherently difficult and past evidence on their size and impact in healthcare markets has generally been limited to surveys (Cunningham and O’Malley, 2008; Casalino et al., 2009; Morra et al., 2011; Long, 2013) or accounting exercises (Pozen and Cutler, 2010; Tseng et al., 2018).

We use data from an obscure part of the billing system, called "remittance data," to examine whether administrative frictions consume healthcare resources, and consequently distort the availability of care. Doctors and insurers often have trouble determining what care a patient's insurance covers, and at what prices, until after the treatment occurs. This ambiguity leads to a costly billing and bargaining process after care is provided - what we call the costs of incomplete payments (CIP). We estimate these costs across insurers and states. We then show that CIP impact Medicaid patients' access to medical care. This impact is quantitatively as relevant as physician payment rates, which are known to influence physicians' acceptance of Medicaid patients (Polsky et al., 2015; Oostrom, Einav and Finkelstein, 2017; Candon et al., 2018; Alexander and Schnell, 2019), and the supply of care more broadly (Gruber, Kim and Mayzlin, 1999; Clemens and Gottlieb, 2014; Dunn and Shapiro, 2018; Gottlieb et al., 2021).

The remittance data capture the billing processes following 90 million visits between 2013-2015. We observe repeated interactions between insurers and physicians, along with information about the patient and the reasons payments are denied. These data provide far more detail about the billing process than the claims data that have become widely used to study healthcare markets. Combined with a model, they enable us to estimate empirically

\footnotetext{
${ }^{1}$ National health expenditure comprised nearly 18 percent of GDP in 2019, before COVID increased that figure to nearly 20 percent in 2020 (Centers for Medicare and Medicaid Services, 2020). Centers for Medicare and Medicaid Services (2019) reports that 73 percent of this 18 percent was paid by a health insurer.
} 
the costs of haggling between the physician's practice and the insurer.

Payment frictions are particularly large when billing Medicaid - a key part of the U.S. social safety net, which generally provides less access to care than other insurance (Polsky et al., 2015; Candon et al., 2018; Oostrom et al., 2017). We find that 24\% of Medicaid claims have payment denied for at least one service upon doctors' initial claim submission. Denials are much less frequent for Medicare (6.7\%) and commercial insurance (4.1\%). Following a denial, the physician can accept that the claim won't be paid, foregoing the potential revenue, or she can commence a back-and-forth process to quarrel with the insurer over payment.

We show that physicians are more likely to undertake this process when the financial stakes are larger, and when more likely to successfully collect revenues. We leverage this empirical observation and a model of rational dynamic billing decisions to estimate CIP across insurers and states. In the model, doctors (or their billing offices) maximize total expected revenues net of administrative costs, under rational expectations about the probability of future denials and future resubmissions. Using the conditional choice probability method (Hotz and Miller, 1993) we estimate expected continuation values for each feasible resubmission decision, and obtain maximum likelihood estimates of the costs of resubmitting claims.

Our CIP estimates incorporate two concepts: expected foregone revenues and expected additional billing costs that providers incur during the back-and-forth negotiations with insurers. We estimate that CIP average $17.6 \%$ of the contractual value of a typical visit in Medicaid, $4.7 \%$ in Medicare, and $2.4 \%$ in private insurance. These are significant sharesespecially for Medicaid, which offers physicians much lower reimbursement rates than other insurers in the first place. In addition to these differences across insurers, we also find significant variation in CIP across states.

The magnitude and variation raise a natural question: does CIP affect physicians' supply of care? We test this using the federalist structure of Medicaid, the federal-state program that insures lower-income adults, pregnant women, and children. While it is largely federally 
financed, and subject to federal regulations, Medicaid is administered separately by each state - often via contracts to managed care organizations. This structure enables dramatic variation in physician payment rates and processes, driving the empirical variation we find. By adjusting our CIP estimates and fees for patient composition and physician billing skills, we generate state-by-insurer price and CIP indices driven purely by insurance administration.

We combine these indices with administrative data on all physicians' locations and survey data on the near-universe of physicians' Medicaid and Medicare participation decisions from 2009-2015. Our key outcome is whether the physician accepts Medicaid patients when practicing in a given state, in a given year. To avoid confounding due to physicians who are capacity constrained, we focus on physicians who accept Medicare patients; our results are robust to relaxing this restriction. ${ }^{2}$

We use two strategies to identify the impacts of Medicaid prices and CIP. The first studies providers who move across states (Abowd, Kramarz and Margolis, 1999; Finkelstein, Gentzkow and Williams, 2016; Hull, 2018; Molitor, 2018). Second, we compare physicians' Medicaid acceptance across clinic locations that operate in different states but are managed by the same physician group. The first strategy controls for any differences in individual physicians' specialization or preferences, such as the level of altruism towards Medicaid patients. The second strategy addresses the possibility that a group's managerial competence or organizational structure influences Medicaid acceptance decisions. ${ }^{3}$

Examining physicians who move across states, a one-standard-deviation increase in CIPapproximately ten percentage points - reduces physicians' probability of accepting Medicaid patients by 0.8 percentage points. This is larger than the effect of a one-standard-deviation

\footnotetext{
${ }^{2}$ One issue when constructing CIP indices is that we can only measure CIP for visits that actually took place. If doctors avoid Medicaid patients when expected CIP are high, the observed visits would be non-randomly selected. To address this concern, we construct a version of CIP indices with a Heckman (1979) selection correction, exploiting county-year variation in the share of the population that is covered by Medicaid, which varies the probability that a visit exists in the sample.

${ }^{3}$ Within both strategies, we instrument for the state's CIP index using an index derived only from claim denial information. We do this to isolate variation in CIP that is independent of variation in prices, to ensure that any measurement error in prices does not contaminate our estimates of how physicians respond to CIP.
} 
increase in Medicaid reimbursement rates, which increases the probability of accepting Medicaid patients by 0.6 percentage points. Looking across states within physician group, a one-standard-deviation increase in CIP decreases the probability of accepting Medicaid by 1.5 percentage points, while a one-standard-deviation increase in fees increases Medicaid acceptance by 2.2 percentage points. ${ }^{4}$

These results introduce and quantify a new form of policy leverage that regulators and insurers implicitly use to control access to care, particularly in Medicaid. We use our model of optimal resubmissions, together with the estimated effects of CIP and prices on Medicaid acceptance, to quantify the tradeoffs at stake. We find that decreasing prices by 10 percent, while simultaneously reducing the denial probability by 20 percent, could hold Medicaid acceptance constant while saving an average of $\$ 10$ per visit.

Although billing processes are costly for physicians, insurers, and patients, they could have offsetting benefits that we do not capture. ${ }^{5}$ So our $\$ 10$ per visit estimate can be interpreted as a minimum value these non-modeled reasons must provide Medicaid in order for denials to be efficient. Although analyzing such benefits is an important direction for further research, the market-shrinking effect of patients losing access to care that we measure here would remain an important tradeoff.

A second limitation is that we only explore one dimension of administrative hassle in healthcare. Beyond the payment process we study, other forms of administrative hassle across (Cutler, 2020) and within (Bloom et al., 2015) healthcare institutions could also contribute to foregone efficiency.

Prior to our study, the relationship between billing hassle and physician behavior has been

\footnotetext{
${ }^{4}$ These results are robust to alternative specifications, including using OLS rather than instrumenting with denial indices, to including all physicians rather than only those accepting Medicare, to implementing a selection correction when estimating CIP indices, and to controlling for the share of Medicaid enrollees who are covered by a private MCO.

${ }^{5}$ Denials may be part of a process to direct treatment decisions towards more appropriate or cost-effective care (Shi, 2022), or to target programs towards more appropriate providers. Preauthorizations may serve a similar role (Brot-Goldberg, Burn, Layton and Vabson, 2022; Eliason, League, Leder-Luis, McDevitt and Roberts, 2021). Importantly, denials may deter fraud, as Crocker and Morgan (1998); Crocker and Tennyson (2002); Dionne, Giuliano and Picard (2009) consider.
} 
explored in small descriptive surveys (Sloan, Mitchell and Cromwell, 1978; Cunningham and O'Malley, 2008; Long, 2013; Ly and Glied, 2014). In the hospital inpatient context, Gowrisankaran, Joiner and Lin (2019) show that electronic health records and Medicare payment policies interact in subtle ways to drive coding and billing. Zwick (2021) makes a similar point in a very different setting (corporate taxation): accountants' sophistication influences the tax deductions that firms claim.

The fact that insurers' claim denials shrink the market is related to a prediction of Gennaioli et al. (2020). In their model, markets with more claim denials have less insurance sold. Here we identify a distinct, novel channel by which administrative burdens shrink the market: deterring the physicians needed to make health insurance an attractive product. This effect represents a new angle to the public finance literature that considers administrative ordeals facing potential program beneficiaries. These ordeals may (or may not) improve program targeting (Nichols, Smolensky and Tideman, 1971; Nichols and Zeckhauser, 1982; Besley and Coate, 1992; Finkelstein and Notowidigdo, 2019; Deshpande and Li, 2019). In other contexts, program complexity deters beneficiaries' participation in SSI (Bound and Burkhauser, 1999), food stamps (Currie, Grogger, Burtless and Schoeni, 2001), and student aid (Dynarski and Scott-Clayton, 2006).

Finally, our work speaks directly to the empirical literature on sequential bargaining and negotiated price settings (Keniston, 2011; Larsen, 2014; Jindal and Newberry, 2015; Hernandez-Arenaz and Iriberri, 2018; Bagwell, Staiger and Yurukoglu, 2020; Backus, Blake and Tadelis, 2019; Backus et al., 2020), and relates to rationality and transaction costs in presence of incomplete contracts (Tirole, 1999). Backus et al. (2020) provide an extensive review of this empirical literature, which Fudenberg, Levine and Tirole (1985) inspired. As in Backus et al. (2020), we are in the rare position to observe a large dataset that, for a key industry such as healthcare, contains the entire sequences of communications and proposed trades between parties. This enables us to estimate economic costs of resubmitting claims, and document how costly bargaining over payments shrinks the availability of care. 


\section{Institutional Background and Data}

\subsection{Billing in the U.S. Healthcare System}

We begin with an overview of the U.S. health insurance billing process, which is critical to understanding our data and analysis. Figure 1 provides a schematic overview of this process. When insured patients visit physicians, they rarely make up-front payments. Instead, the medical practice submits a bill to the patient's insurer after the visit. This process is similar for commercial insurers - such as insurance plans sponsored by employers (Einav, Finkelstein and Cullen, 2010; Bundorf, Levin and Mahoney, 2012) or purchased in a health insurance marketplace (Ericson and Starc, 2015; Shepard, 2022; Tebaldi, 2022) - and public insurers, such as Medicare (Curto, Einav, Levin and Bhattacharya, 2021) for the elderly and Medicaid (Dranove, Ody and Starc, 2021) for lower-income beneficiaries.

The first step in billing is to determine exactly which of the 13,000 services defined by the "Healthcare Common Procedure Coding System" (HCPCS) the physician provided. ${ }^{6}$ A claim may contain one or more line items, each containing one HCPCS code. The physician or biller must classify the patient's diagnosis using International Classification of Diseases (ICD) codes, and collect and report the patient's personal details and insurance coverage.

Once the information is prepared, the biller submits a claim to the patient's insurer. The information required and method of submission are standardized for the initial claim. ${ }^{7}$ Using a specific format established by the federal government, the physician provides the insurer with identifying information for the patient and his insurance plan, the treatment provided (using HCPCS codes), the diagnosis (ICD) codes that justify that treatment, and the amount she would like to be paid (the "billed charge"). ${ }^{8}$

\footnotetext{
${ }^{6}$ These codes range from an outpatient visit for a new patient (codes 99201-99205, depending on visit complexity) to an influenza test (code 87804) to a fetal ultrasound (generally code 76801 in the first trimester and 76811 thereafter, but with different codes depending on the thoroughness, method, and for multiple pregnancies).

${ }^{7}$ The standard CMS Form 1500 has been supplanted by its electronic version EDI 837 (established by HIPAA), and insurers respond with Electronic Remittance Advice EDI 835 described in detail below.

${ }^{8}$ These billed amounts are infamously outrageous and, with one minor exception described in Appendix A.2, we do not use them in our analysis. (Though they may sometimes provide a baseline for rate negotiations. In the hospital payment context, Reinhardt (2006) describes these list charges and Cooper et al. (2018) find
} 
The insurer receives the claim from the biller, analyzes it, and adjudicates it. At the initial stage, this processing and decision may be handled by a third-party contractor acting on behalf of the insurer, primarily using an automated system containing payment and audit rules. This system determines whether the patient has eligible insurance, whether the insurance covers the service provided, and whether the medical care was appropriate. ${ }^{9}$

When this evaluation is complete, the insurer makes a payment decision regarding the claim. When the insurer decides to pay, its system must determine the relevant contractual payment for each line item. This amount should follow from an existing regulation or contract: for public insurance, the (state or federal) government establishes the rates by legislation and regulation. For commercial insurance, the insurer and physician will have agreed on a set of payment rules in advance (see Clemens and Gottlieb, 2017, for more details).

The insurer transmits its decision to the physician using a standardized electronic format, called Electronic Data Interchange 835, "Electronic Remittance Advice," to which we refer as simply a "remittance." These remittances tell the physician whether the insurer has approved the claim, how much money to expect from the insurer (the "paid amount"), and how much to collect from the patient. Depending on the physician's billing arrangement, the remittances may be sent straight to the physician's practice or to a clearinghousean intermediary contracted to process the practice's claims. If the process goes smoothly, the only remaining step is to collect payment. The insurer should transmit its part of the payment directly to the practice, which bills the patient for any cost-sharing they owe.

But the process is not always smooth. The insurer may deny the claim in full or in partrefusing payments for specific line items - or authorize less payment than the doctor was expecting. This can reflect questions about the validity of the patient's insurance coverage, the medical justification for a specific procedure, whether the physician submitted erroneous

that they still form an important part of many hospitals' payment contracts.)

${ }^{9}$ The insurer can also use this opportunity to look for any fraudulent claims, although there are questions about how thoughtfully they do this (Allen, 2019) and whether they even have incentives to do so (Cicala, Lieber and Marone, 2019). 
codes, or whether the patient's contract covers the care provided. ${ }^{10}$

When a claim (or part of it) is denied, the process can continue in a few different ways. The physician can give up on the claim and write off the lost revenue. ${ }^{11}$ Alternatively, she can prepare a new claim in an attempt to change the insurer's decision and collect payment. The precise steps required depend on why the claim was denied. If the insurer questioned the medical necessity of the treatment, the physician may have to provide additional documentation about the patient's condition by fax or through an online submission. If there was an administrative error, such as a typo in the patient's name or insurance details, the practice may need to submit corrected information. If the physician thinks that the claim adjudication does not comply with her contract, she may have to submit a formal appeal to the insurer, requiring manual intervention and a decision by someone higher in the insurer's hierarchy. Each time the insurer processes the claim, it generates a new remittance.

\subsection{Remittance Data}

Our primary data source is IQVIA Real World Data-Remittance Claims, introduced and summarized by Gottlieb, Shapiro and Dunn (2018). IQVIA obtains these data from clearinghouses that receive the remittances on physicians' behalf. Since the physician practice chooses which clearinghouse to work with, our sample is effectively drawn at the physician level. ${ }^{12}$ For more than 100,000 unique physicians covered in the sample, we observe their interactions with the full range of insurers, including Medicaid, Medicare, and commercial.

We see the remittances generated each time the insurer responds to a physician's submis-

\footnotetext{
${ }^{10}$ The organization that manages the Electronic Data Interchange standards maintains a list of around 350 codes for different reasons claims may be adjusted or denied (see http://www.x12.org/codes/claim\% 2Dadjustment\%2Dreason\%2Dcodes/, accessed on 8/13/2022).

${ }^{11}$ If she has not signed a payment contract with the insurer (i.e., she is "out-of-network") she may be able to bill the patient directly for any missing revenue. But in the more common situation where the physician has a contract with the insurer ("in-network"), that contract likely forbids her from collecting amounts the insurer has not authorized. So in most cases the physician's only option is to deal with the insurer directly.

${ }^{12}$ Since the data provider includes remittance data from whichever clearinghouses it contracts with, rather than a systematic random sample, one may naturally worry about the sample's representativeness. Upon introducing our data, Gottlieb et al. (2018, online appendix) showed that physicians appear very representative of the covered specialties nationwide; this supports the nationwide representativeness of our results.
} 
sion or resubmission-including those remittances indicating claim denial or nonpayment. For each remittance, the data tell us the providing physician, the practice submitting the bill, its zip code, and the insurer providing the remittance. We see the detailed procedure (HCPCS) codes indicating what care was provided, ICD diagnosis codes, and key dates: when the service was provided, when the claim was submitted, and when the insurer made its decision. We then see how the insurer handled the claim, including the summary of its decision for each procedure (paid, denied, etc.), justification for any adjustments to individual service lines, and how much it is paying. At the patient level, a de-identified code allows us to link the same patient across remittances, and we observe the patient's age. ${ }^{13}$

Note on Terminology. In what follows, line item value refers to the contractual amount for a specific procedure for which the physician bills; i.e. it is the amount that the provider would receive if there were no denials. This is simply the observed allowed amount for all claims that are processed smoothly, and otherwise we must impute it. Appendix A.2 describes our imputation process. We use the term claim value when referring to the total of line item values for a claim. The initial claim value is the claim value for the first claim submitted for a visit. ${ }^{14}$ This is the revenue that the provider would collect absent denials.

Summary Statistics. Table 1 offers a first look at our remittance data. Across the 81.4 million visits we observe from 2013-2015, the average initial claim value is $\$ 155$, the 10 th percentile is $\$ 30$, and the 90 th percentile is $\$ 240$. Visits differ along several dimensions, including the number of line items included. The average visit contains 1.8 line items; ten percent of visits contain three or more.

A key variable for our analysis is whether the insurer denied payment for at least one line item in a claim for a given visit. Table 1 shows that, across all insurers and all years in

\footnotetext{
${ }^{13}$ Appendix A provides additional details on the construction of our estimation dataset, including the preprocessing leading to our main sample, and the steps to determine the terms of insurer-physician contracts.

${ }^{14}$ It may differ from the value of subsequent claims for the same visit because the payer may only pay a subset of line items and the provider may choose not to resubmit all line denied items.
} 
our sample, $7 \%$ of visits contain at least one line item for which payment is denied. Since providers can resubmit claims for the same visit after denials, the average number of claims submitted for each visit is 1.04 . $8 \%$ of visits in our sample are billed to Medicaid, $46 \%$ to Medicare, and $47 \%$ to commercial insurers.

The three types of insurers differ in three key dimensions: the amounts that would be paid if there were no denials, the frequency of denials, and providers' ability to collect payments after denials. Table 2 summarizes these differences. The initial Medicaid claim value averages $\$ 102$, but one quarter of visits have at least one line item denied upon initial submission. After the sequence of resubmissions and denials that follows, providers receive $\$ 87$ on average. Medicare and commercial insurers have higher mean initial claim values $(\$ 135$ and $\$ 183$, respectively) and lower denial rates (6.7\% and 4.1\%). Accounting for resubmissions, the total revenue collected for Medicare patients averages $\$ 130$ per visit, and $\$ 178$ for patients covered by commercial plans.

Table 2 also highlights the multi-period aspect of the billing process following initial denials. After the first denial takes place, 34-62 percent of visits (depending on insurer) see only one claim resubmission. 4.8-6.6 percent of visits go to a second round of resubmission, and 2-3.4 percent of visits go to a third or higher round. So we must consider physicians' beliefs about future denials and the future billing costs they will incur to recover revenues, beyond the initial resubmission.

Table 3 illustrates in richer detail the differences in billing processes across insurers, and how denial reasons relate to payment outcomes. ${ }^{15}$ Summarizing data at the line item level,

\footnotetext{
${ }^{15}$ When a line item is denied payment, we observe a code capturing the denial reason. Since there are hundreds of reason codes, our analysis aggregates them into five mutually exclusive categories: administrative, contractual, coverage, duplicate, and information. Administrative problems include exceeding the time limit for filing a claim; the negotiated rate is not on file or has expired; or prior claim adjudication. The contractual category indicates denials specified in the insurer contract, such as "procedure has a relative value of zero in the jurisdiction fee schedule, therefore no payment is due," or "this procedure is not paid separately." Coverage problems indicate claim denial because the patient isn't insured ("Expenses incurred prior to coverage" or "Expenses incurred after coverage terminated"), the plan doesn't cover the service in question, or the provider is ineligible. Duplicate claims are straightforward: "Exact duplicate claim/service." We use the "information" category to describe denials when the insurer reports insufficient information to pay - such as a lack of medical justification, preauthorization, or referral. Supplementary Appendix Figure S.1 uses word clouds to summarize the explanations for all the denial reasons within each category.
} 
rather than the visit, this table shows remarkable differences across insurers in denial reasons. Administrative reasons comprise one quarter of denials in Medicaid, $16 \%$ in Medicare, and $14 \%$ in commercial insurance. Contractual reasons drive $31 \%$ of denials in Medicaid, $39 \%$ in Medicare, and $60 \%$ in commercial insurance.

Differences in denial reasons are associated with different resubmission decisions and ability to recover revenues. When a line item is denied for administrative reasons, we observe a second claim for the same visit $39 \%$ of the time in Medicaid, $57 \%$ in Medicare, and $26 \%$ in commercial insurance. After these billing processes end, providers ultimately recover $58 \%$ of revenues in Medicaid, $94 \%$ in Medicare, and $72 \%$ in commercial insurance. Other reasons for denials lead to different outcomes. For example, coverage issues imply a $32 \%$ recovery rate in Medicaid, 34\% in Medicare, and $67 \%$ in commercial insurance. When the insurer requires additional information before authorizing a payment for a line item, only $29 \%$ of Medicaid revenue is recovered, compared to more than $40 \%$ for both Medicare and commercial insurance.

The key empirical patterns for our analysis are the relationships between the value of line items, the probability of denials, and the decision to incur billing costs to resubmit claims. Figure 2 summarizes these relationships. For each insurer, we show the histogram of average value for each procedure code in the initial claims. The differences in these distributions confirm that Medicaid tends to pay less than Medicare, which in turn tends to pay less than commercial insurance.

The dots in Panels (b), (d), and (f) all show that the probability of resubmission is increasing with line item value. This provides initial evidence that physician resubmission decision are consistent with rational, profit-maximizing behavior, when facing positive resubmission costs: incurring those costs is more likely to be worthwhile when more revenue is at stake. ${ }^{16}$ In contrast, Panels (a), (c), and (e) do not show a pattern of insurers denying

\footnotetext{
${ }^{16}$ However, these empirical relationships on their own are not sufficient to prove this point, or to estimate the resubmission costs, because they don't account for (1) the probability that a resubmission will succeed, (2) the probability that, when it doesn't, the physician will incur future resubmission costs, or (3) heterogeneity across claims. Our model in Section 3 addresses these issues.
} 
payment for higher-value services; if anything, the public insurers are less likely to deny more valuable services. This might suggest that physicians pay more attention when billing procedures with higher value.

\subsection{Additional Data Sources}

We complement our data with two additional sources, summarized in Table 4. The Centers for Medicare and Medicaid Services provides a dataset that it regularly updates with information on physicians' specialty, location, and practices. We use this file, called Medicare Data on Provider Practice and Specialty (MD-PPAS), to identify where physicians are located and when they move. We also use the tax identifiers it provides to identify those who work in the same practice.

We augment the administrative physician characteristics from MD-PPAS with SK\&A survey data also purchased from IQVIA. These data, primarily collected by the firm for marketing purposes, come from administrative records and a manual phone survey of most practicing U.S. physicians. Among the key questions for our purposes, SK\&A asks whether each physician accepts Medicare patients and Medicaid patients. ${ }^{17}$ To measure the behavior of physicians who are plausibly marginal to the variation we observe, we limit our study of Medicaid acceptance to those physicians who report accepting Medicare patients, though our results are similar when relaxing this restriction. As we show later, Medicaid generally pays less and has higher CIP than Medicare, so physicians who refuse Medicare patients would have even less economic reason to treat Medicaid patients and are unlikely to be responsive to Medicaid variation.

The resulting dataset contains 3.7 million provider-year observations over the 2009-2015 period. Physicians report accepting Medicaid patients $72 \%$ of the time, and accepting Medicare patients $84.1 \%$ of the time. We view this 84.1 percent as the relevant universe; of these, $80.3 \%$ accept Medicaid. In the same period, $1.1 \%$ of doctors move across different states and

\footnotetext{
${ }^{17}$ In Appendix A.3 we compare the patterns in Medicaid acceptance from this survey to the patterns observed in the IQVIA sample.
} 
$27.3 \%$ of them work in a group that has locations in more than one state. ${ }^{18}$

\section{Billing Hurdles and Costs of Incomplete Payments}

The patterns in the remittance data highlight two sources of financial losses that a physician can experience after providing medical services. First, she might be partly or fully unable to collect expected revenues. Second, when trying to collect revenues after a claim is denied, she incurs additional administrative costs to address the denial and submit a new claim.

We define the costs of incomplete payments (CIP) as the expected financial losses due to revenues that are never collected plus administrative costs for resubmissions. Formally, for a given visit, let $L$ be the set of line items in the initial claim, and $\pi(L)$ denote the total initial claim value. The CIP for the visit is then

$$
C I P \equiv \underbrace{\pi(L)-\mathbb{E}[\text { collected revenues }]}_{\mathbb{E}[\text { foregone revenues }]}+\mathbb{E}[\text { resubmission costs }]
$$

Rather than $\pi(L)$, the expected revenue for the visit is $\pi(L)(1-\tau)$, where

$$
\tau \equiv \frac{C I P}{\pi(L)}
$$

is CIP as a share of the visit's value. While collected revenues are observed in the remittance data, to compute $\tau$ we must estimate resubmission costs.

To do this, we model resubmissions as the solution of a single agent dynamic decision problem. When resubmitting a claim, a physician knows that future denials are possible, so further resubmissions might be necessary to recover revenues. These dynamic considerations reflect the patterns observed in the remittance data. ${ }^{19}$ We assume that physicians have rational expectations about billing processes, and that they behave optimally when choosing

\footnotetext{
${ }^{18}$ Appendix A.3 illustrates the Medicaid acceptance patterns within physician groups, and examines the frequency with which physicians change their Medicaid acceptance decision around a move.

${ }^{19}$ Table 2 shows that, after the initial denial, the back and forth between physician and insurer can continue to third, fourth, or even later rounds of resubmissions.
} 
whether and which line items to resubmit.

We treat the set $L$ of services provided in a given visit as exogenous. In Appendix A.4, we provide evidence to support this assumption by exploring the relationship between the probability that a procedure is administered and its likelihood of having payment denied..$^{20}$

\subsection{The Resubmission Problem}

Consider a visit $j$ with characteristics $X_{j}$ (e.g. insurer, diagnosis, procedure, and initial claim value), in which the physician provided a set of procedures $L_{j}$. Our model begins when the insurer denies a set of line items $D_{j} \subset L_{j}$ with reason code indexed by $\rho$. The physician $i$, with characteristics $Z_{i}$ (including practice size and state), has to decide whether to resubmit a claim for the visit. Doing so would incur administrative costs that depend on the reason for denial, on the physician, visit, and insurer characteristics, and on the number of line items in the new claim. Specifically, when resubmitting the set of line items $R_{j} \subset D_{j}$, the physician incurs administrative costs of

$$
C_{i j}\left(R_{j}\right)=\mu\left(\left|R_{j}\right|, X_{j}, Z_{i}, \rho\right)+\varepsilon_{i j}
$$

where $\left|R_{j}\right|$ is the number of resubmitted line items and $\varepsilon_{i j}$ is an idiosyncratic error term drawn from a Type 1 extreme value distribution. Our goal is to estimate the parameters of the function $\mu$, assuming that physicians have rational expectations and maximize expected future payoffs after the visit. As detailed in Appendix B, we let $\mu$ vary flexibly by payer, state, reason code, and (in the richest specifications) size of physician practice. The number of line items in the claim enters $\mu$ linearly.

\footnotetext{
${ }^{20} \mathrm{~A}$ more subtle form of endogeneity would be if physicians adjust intensity of care within procedure (for instance, by providing the service more often or spending more time with the patient) to the presence of billing hurdles. Since we see no response on the extensive margin of procedure choice, we do not delve further into potential intensive margin responses. In subsequent work, Shi (2022) and Brot-Goldberg et al. (2022) study the impacts of hospital audits and drug pre-authorization, respectively - also focusing on extensive margins of healthcare use, such as whether to admit the patient as an inpatient, or whether to consume the drug. (Though the hospital spending outcome in Shi (2022) and the substitution across drugs in Brot-Goldberg et al. (2022) could be viewed as intensive margin responses.)
} 
For a given function $\mu$, the probability that physician $i$ resubmits the set of line items $R_{j}$ after the line items in $D_{j}$ are denied is

$$
\operatorname{Pr}\left[R_{j} \mid D_{j}, X_{j}, Z_{i}, \rho\right]=\frac{\exp \left[-\mu\left(\left|R_{j}\right|, X_{j}, Z_{i}, \rho\right)+\delta \mathcal{V}\left(R_{j}, X_{j}, Z_{i}, \rho\right)\right]}{\sum_{R^{\prime} \subset D_{j}} \exp \left[-\mu\left(\left|R^{\prime}\right|, X_{j}, Z_{i}, \rho\right)+\delta \mathcal{V}\left(R^{\prime}, X_{j}, Z_{i}, \rho\right)\right]}
$$

where $\delta$ is the intertemporal discount factor, which we set to $0.99,{ }^{21}$ and $\mathcal{V}\left(R_{j}, X_{j}, Z_{i}, \rho\right)$ denotes the expected continuation value after resubmitting $R_{j}$, conditional on $X_{j}, Z_{i}, \rho$.

In Appendix B we derive equation (4) following Hotz and Miller (1993). Their conditional choice probability method allows us to estimate the value function $\mathcal{V}$ directly from the remittance data, and we estimate the parameters of the function $\mu$ via maximum likelihood.

\subsection{Identification of Resubmission Costs}

To identify the parameters of the function $\mu$ governing resubmission costs, we exploit the joint variation in resubmission decisions, denied amounts, and expected repayment probabilities, conditional on $X_{j}, Z_{i}, \rho$. Figure 2 illustrates this variation in the raw data.

Ignoring resubmissions in later periods, the payoff from resubmitting a claim is increasing in expected revenue from this resubmission. Expected revenue is the product of the claim value and the expected recovery rate (i.e. the fraction of the resubmitted claim value that the insurer will pay). Different values of $\mu$ imply different resubmission probabilities as a function of claim value and probability of collection. If resubmission costs are higher, the probability of collection must increase in order to obtain the same resubmission probability for a given claim value.

For a simplified example, consider two pediatric visits with new patients: an infant whose visit costs $\$ 100$ and a 10 -year-old whose visit costs $\$ 80$ according to usual payment rates.

\footnotetext{
${ }^{21}$ Although the calendar time between one denial and the next is variable, we disregard these differences and simply treat each submission as one time period. Typical periods observed in the sequences of remittances following a visit are shorter than three months; we set $\delta=0.99$ following Ahmed, Haider and Iqbal (2012). Gottlieb et al. (2018) show that the actual response time varies across insurers, so a richer analysis could incorporate differences in discounting due to the variation in delays.
} 
Suppose both claims are denied, and we see that resubmissions for both visit types have a 20 percent success rate. We assume that patient age does not affect resubmission costs. So if the doctor chooses to resubmit the claim for the infant's visit but not the 10-year-old's, we infer that the doctor's resubmission cost would have been between $\$ 16$ and $\$ 20$.

Our approach to identify the parameters in $\mu$ refines this intuition. In particular, we calculate the continuation values of every available resubmission decision, assuming that providers behave rationally when solving the dynamic resubmission problem. Figure 3 shows the empirical relationship between the probability that a set of denied line items is resubmitted, and the expected continuation value estimated with the remittance data.

The extent to which providers make decisions that seem consistent with forward-looking, revenue-maximizing behavior is striking. The sharp monotonic relationship between continuation values and probability of resubmission provides information about resubmission

costs. Appendix Table A.3 further illustrates the difference between continuation values across observed and counterfactual resubmission choices. The continuation values for the set of line items that physicians resubmit are significantly higher than for the non-chosen alternatives. Resubmission costs are identified by treating observed resubmissions as optimal up to idiosyncratic errors, and treating the continuation values as known. We exploit residual variation as exogenous after conditioning on payer, state, reason code, initial claim amount, and size of physician groups (and, in our richest specifications considered in the Supplemental Appendix, individual diagnosis and procedure codes).

\subsection{Estimates of Resubmission Costs and Costs of Incomplete Payments}

\subsubsection{Resubmission Costs}

Figure 4 summarizes the estimated resubmission costs for claims with one line item, varying across payers, states, reason codes, and size of physician practice. Appendix Table A.4 shows the details of all parameter estimates. We estimate that resubmitting a claim to Medicaid costs the physician office $\$ 14$ on average. This value ranges across type of claims and states, 
from near zero to over $\$ 40$ per resubmission. These estimates are sizable, representing $14 \%$ of the mean initial claim value and $16 \%$ of collected revenues. They line up with prior estimates based on time accounting (Tseng et al., 2018; CAQH, 2020). ${ }^{22}$

Resubmission costs for Medicare claims are generally lower, averaging $\$ 10$, and less dispersed. This is consistent with Medicare administration being coordinated at a more aggregate level, rather than state-by-state, as well as a larger volume of patients leading to more experience in solving billing issues.

Resubmitting claims to commercial insurers (which occurs rarely compared to Medicaid and Medicare) is more expensive on average, and dispersed. Our estimates for commercial payers show an average resubmission cost of $\$ 17$, with significantly more mass above $\$ 30$.

\subsubsection{Costs of Incomplete Payments}

We use our estimated resubmission costs to compute the expected CIP and $\tau$ for each visit in our data. Table 5 reports the averages of these measures. The table contains three panels, one for each category of insurance, each with five model specifications (shown in separate columns). Within each panel, the top row reports the average $\tau$ and the second row the average CIP implied by that model across all visits in our estimation sample. ${ }^{23}$

The first model for each insurer disregards resubmission costs, i.e. it imposes $\mu$ constant and equal to 0 . The CIP in this case come only from the revenue ultimately not collected. We estimate CIP of $\$ 9.75, \$ 2.66$ and $\$ 1.79$, corresponding to $\tau$ of $0.141,0.033$, and 0.019 for Medicaid, Medicare, and commercial insurance, respectively. ${ }^{24}$

These numbers increase significantly once we incorporate the resubmission costs. The

\footnotetext{
${ }^{22}$ While the settings and specific numbers reported are slightly different, both sources are in the same ballpark. For instance, CAQH (2020) reports that a claim status inquiry costs a provider $\$ 9.37$ when completed manually, and merely processing a remittance advice $\$ 3.96$. Tseng et al. (2018) report that billing costs $\$ 20.49$ for a primary care visit and $\$ 215.10$ for an inpatient surgery.

${ }^{23}$ Appendix Table A.4 presents a more detailed version of this table that reports the average parameter estimates for the function $\mu$ defined in Section 3.1, as well as standard errors (which we omit from Table 5 to economize on space). Supplementary Appendix Tables S.1 and S.2 report estimates from further versions of the model in which we relax some of the main model's assumptions (detailed in Appendix B).

${ }^{24}$ As Appendix A.1 details, we eliminate outliers from our estimation sample, which lowers the estimates of CIP and $\tau$. This is another reason these estimates should be viewed as conservative.
} 
second model for each insurer implements this in a simple way, estimating parameters of $\mu$ that do not depend on the denial reason. Expected CIP increase to $\$ 12.43, \$ 3.94$, and $\$ 2.36$, and $\tau$ to $0.174,0.047$, and 0.024 for the three types of insurance, respectively.

The third model for each insurer is richer, estimating $\mu$ separately based on the denial reason. The average $\tau$ and CIP change little, but Appendix Table A.4 shows that the estimated resubmission costs differ substantially by denial reason.

In the final two columns, we estimate this richest model separately for smaller and larger physician groups. We find that smaller groups incur higher resubmission costs across all insurance categories. Small groups' costs are about 8 percent higher than large groups' when billing Medicaid, and 30-40 percent higher (though on a much smaller base) when billing Medicare or commercial insurance. Qualitative patterns according to denial reason are similar across group size (see Appendix Table A.4). We take this richer model as our baseline for the rest of the paper. ${ }^{25}$

Figure 5 shows that there is meaningful variation in CIP and $\tau$ across states, particularly in Medicaid. Expected CIP ranges from less than $\$ 5$ to more than $\$ 30$, while the CIP share $\tau$ is higher than 0.25 in Texas, Illinois, and Pennsylvania, and lower than 0.1 in Colorado and Idaho. In contrast, except for Medicare in Alaska, no state's $\tau$ exceeds 0.1 for either commercial insurance or Medicare.

\section{Do Billing Hurdles Keep Physicians Away from Medicaid?}

We now ask whether CIP affect physicians' behavior. Intuitively, rational physicians would care about the net revenue $\pi(L)(1-\tau)$, and not simply about the prices $\pi(L)$. While physicians may respond to this net reimbursement along a variety of margins, we focus on one of the simplest and most extreme: the choice of whether to treat Medicaid patients. We

\footnotetext{
${ }^{25}$ We have considered finer definitions of group size, but estimated meaningful differences only between the two categories shown here. One could alternatively let size affect resubmission costs (and strategies) parametrically, but we prefer a flexible approach. We use only these two size bins because further granularity causes us to lose visits for which we do not have enough observations within each combination of conditioning variables, without revealing additional economic content.
} 
focus on Medicaid because, as Figure 5 shows, it has substantial variation in CIP, which enables our estimation. As Table 4 shows, Medicaid also has low physician participation rates - a relevant margin along which physicians could respond to CIP.

This margin - refusal to treat Medicaid patients - is a natural focus because of the uncertainty inherent in the CIP. By its very nature, CIP is the mean over a risky distribution: physicians know that Medicaid will deny many payments, and billing will be costly, but may not know exactly which claims will be denied. Even if they did know, it may be difficult to supply care selectively to Medicaid patients at low risk for claim denial, while refusing those with higher risk. A blanket decision - to accept Medicaid patients or notmay be the easiest margin to adjust. Moreover, the evidence in Appendix A.4 suggests that different treatment choices are not likely to be of first order importance. ${ }^{26}$

\subsection{Indices of Fees and CIP Across States}

We use variation in fees and CIP across states to study physicians' Medicaid acceptance. We first construct state-insurer-specific measures of $\pi$ and $\tau$ that adjust for the composition of visits and physicians' billing skills. ${ }^{27}$ The fee measure is conceptually simple: we would like to know how much more one state's Medicaid program would pay for identical care compared with another state's. Because care is so heterogeneous, we cannot simply compare average prices for all treatments. Other research on Medicaid fees, such as Alexander and Schnell (2019), has had to hand-collect data from each state. This has limited most studies to considering a few specific services, such as primary care. In order to account for the broader set of care included in our sample, we estimate the following regression to compute price indices that account for the plethora of treatments included:

$$
\ln \left(\pi_{\ell j}\right)=\xi_{s, k} \cdot \mathbb{1}_{s(j)} \cdot \mathbb{1}_{k(j)}+\chi_{h} \cdot \mathbb{1}_{h(\ell)}+\varphi_{t} \cdot \mathbb{1}_{t(j)}+\gamma_{1} \text { age }_{j}+\gamma_{2} \text { comorbidities } j_{j}+\epsilon_{\ell j} .
$$

\footnotetext{
${ }^{26}$ Supplementary Appendix Tables S.19 and S.20 examine the share of Medicaid patients physicians choose to treat.

${ }^{27}$ We drop the explicit indication $\pi(L)$ in favor of simply $\pi$ when no confusion might arise.
} 
Each observation in this regression is one service line in one visit; $\pi_{j \ell}$ is the allowed amount for service $\ell$ in visit $j$. Crucially, the regression estimates insurer-by-state fixed effects $\widehat{\xi}_{s, k}$, where $s$ indicates the state and $k$ the insurer. These fixed effects represent the contribution of the state and insurer to explaining the variation in payment level, and they serve as our state-insurer $\log$ fee index. Since the dependent variable is in logs, we can interpret a 0.01 change in $\widehat{\xi}_{s, k}$ as approximately a 1 percent change in the insurer/state's fee. We treat commercial insurance as a single category and omit its indicator, so our index $\widehat{\xi}_{s, k}$ is estimated relative to the national commercial average.

This regression adjusts the raw value, $\pi_{j \ell}$, for the service's and claim's characteristics. Most significantly, we include fixed effects for the specific procedure code, $\mathbb{1}_{h(\ell)}$, and year, $\mathbb{1}_{t(j)}$. We also control for patient characteristics, such as age and other diseases they have, in case these influence the cost.

We estimate a similar index for CIP. We follow the same logic as in equation (5), but replace the dependent variable with $\tau_{j}$, expected CIP as a share of visit $j$ 's value. Unlike with fees, $\tau_{j}$ ranges from zero to one so we do not take its log. First, we compute this following equations (1) and (2), using expected lost revenues and expected resubmission costs conditional on that visit's characteristics. Second, we estimate:

$$
\begin{aligned}
\tau_{j}= & \psi_{s, k} \cdot \mathbb{1}_{s(j)} \cdot \mathbb{1}_{k(j)}+\eta_{i} \cdot \mathbb{1}_{i(j)}+\varphi_{t} \cdot \mathbb{1}_{t(j)}+\sigma_{k, \Sigma} \cdot \mathbb{1}_{k(j)} \cdot \mathbb{1}_{\Sigma(i(j))} \\
& +\theta_{1} \text { age }_{j}+\theta_{2} \text { comorbidities }_{j}+\epsilon_{j} .
\end{aligned}
$$

This specification controls for the individual physician $\mathbb{1}_{i(j)}$ and other visit characteristics that could affect payment difficulty. These controls ensure that our indices reflect differences between comparable medical care rather than differences in physician composition. When controlling for physician, the state-by-insurer indices are identified off of physicians who practice across multiple insurers. $\mathbb{1}_{\Sigma(i(j))}$ is a set of indicators for the size of the physician's group, which we allow to have a different relationship with $\tau$ for each insurer. 
The estimated $\widehat{\psi}_{s, k}$ coefficients serve as our index of the CIP share for each state-byinsurer. The resulting index $\widehat{\psi}_{s, k}$ can be interpreted as capturing differences in the CIP share, with a 0.01 higher value representing a 1 percentage point higher CIP share for the insurer-state pair. ${ }^{28}$

Since we only observe visits for which the physician chose to treat the patient, a natural concern is that the true (unconditional) values of $\tau$ are even larger than what we estimated in Section 3. To address this concern, we apply a Heckman (1979) selection correction for some estimates of equation (6). A natural choice of instrument that does not affect $\tau_{j}$, while affecting the probability that a Medicaid visit takes place - and therefore the observability of $\tau_{j}$ in our sample - is the share of the population in the county-year covered by Medicaid. ${ }^{29}$

Figure 6 shows a scatterplot relating the $\tau$ index $\widehat{\psi}_{s, k}$ and $\log (\pi)$ index $\widehat{\xi}_{s, k}$ across states and across insurers. We show Medicare observations with red circles, and Medicaid observations with state abbreviations. The pattern across insurers is striking: with a few exceptions such as North Dakota, which reimburses Medicaid care quite well, Medicaid generally has lower fees and much higher CIP than Medicare. Medicaid is also notable for the tremendous variance in both dimensions, while Medicare observations are concentrated in the high-fee,

\footnotetext{
${ }^{28}$ Some of the empirical analysis described below also requires an index constructed using only claim denial information, and not relying on the values $\pi_{j \ell}$ (which enter the denominator of $\tau_{j}$ ). We therefore estimate denial-only indices $\psi_{s, k}^{D}$ using a model exactly analogous to (6):

$$
d_{j}=\psi_{s, k}^{D} \cdot \mathbb{1}_{s(j)} \cdot \mathbb{1}_{k(j)}+\eta_{i} \cdot \mathbb{1}_{i(j)}+\varphi_{t} \cdot \mathbb{1}_{t(j)}+\sigma_{k, \Sigma} \cdot \mathbb{1}_{k(j)} \mathbb{1}_{\Sigma(i(j))}+\theta_{1} \text { age }_{j}+\theta_{2} \text { comorbidities }_{j}+\epsilon_{j} .
$$

where $d_{j}$ is an indicator for whether visit $j$ had a denial.

${ }^{29}$ Formally, letting $W_{j}$ denote the population share covered by Medicaid, we estimate the visit-level Probit:

$$
\operatorname{Pr}\left[\text { Patient covered by Medicaid }_{j}\right]=F_{\Phi}\left(\lambda_{1} W_{j}+\lambda_{2} \text { age }_{j}+\lambda_{3} \text { comorbidities }_{j}+\lambda_{t} \cdot \mathbb{1}_{t(j)}\right),
$$

where $F_{\Phi}(\cdot)$ is the standard Gaussian $\mathrm{CDF}$ and $f_{\Phi}(\cdot)$ the corresponding PDF. The estimated parameters of (8) allow us to construct the inverse Mills ratio

$$
\widehat{\mathrm{IMR}}_{j}=\frac{f_{\Phi}\left(\widehat{\lambda}_{1} W_{j}+\widehat{\lambda}_{2} \text { age }_{j}+\widehat{\lambda}_{3} \text { comorbidities }_{j}+\widehat{\lambda}_{t} \cdot \mathbb{1}_{t(j)}\right)}{F_{\Phi}\left(\widehat{\lambda}_{1} W_{j}+\widehat{\lambda}_{2} \text { age }_{j}+\widehat{\lambda}_{3} \text { comorbidities }_{j}+\widehat{\lambda}_{t} \cdot \mathbb{1}_{t(j)}\right)}
$$

We then estimate the following modified version of equation (6):

$$
\tau_{j}=\psi_{s, k} \cdot \mathbb{1}_{s(j)} \cdot \mathbb{1}_{k(j)}+\varphi_{t} \cdot \mathbb{1}_{t(j)}+\theta_{1} \text { age }_{j}+\theta_{2} \text { comorbidities }_{j}+\theta_{3} \widehat{\mathrm{IMR}}_{j}+\epsilon_{j} .
$$

This does not include physician fixed effects, since $W_{j}$ does not vary within physician. 
low-CIP corner of the graph. This is consistent with Medicare being a centralized program, reducing geographic differences in administration. ${ }^{30}$

\subsection{Empirical Strategies}

We are interested in the relationship between each physician's reported willingness to treat Medicaid patients and her state's Medicaid billing hassle and reimbursement rates. For numerous reasons, the observational relationship between these variables need not be causal; for example, physicians who want to treat Medicaid patients may differ from others, or they may select into states with different Medicaid policies.

We use two empirical strategies to address these concerns. Our first strategy uses a physician movers design to address concerns about physician-level characteristics, such as unobservable desire to treat Medicaid patients. In our second strategy, we use physicians in groups that span state boundaries. By controlling for group fixed effects, we account for the possibility that the primary decision-maker is the group, rather than the individual physician. The group's Medicaid acceptance decisions could vary due to practice characteristics such as investment in billing technology, other aspects of billing skill, the group's experience with a particular part of the market, organizational structure (such as not-for-profit status, academic affiliation, or physician leadership) or social mission. The group fixed effects remove such differences and allow us to estimate the impacts of state policy differences even if the organizations play a major role in Medicaid acceptance decisions.

These strategies are complementary because of their different limitations. A limitation of the movers strategy is that physicians might require some time to learn how Medicaid works in their new state, and thus might not respond immediately. Some physicians may also work as part of groups that limit their individual decision-making about which patients to treat. In contrast, the second strategy controls for unobservables at the group level but not for the

\footnotetext{
${ }^{30}$ Supplementary Appendix Table S.3 summarizes variation in these indices, and shows robustness to other choices in data and index construction, such as which controls to include, whether to omit imputed contractual amounts, and weighting. Note that the indices are all normalized to have the mean of the raw data for the respective variable.
} 
individual physician. Even within a group, physicians with a stronger preference for treating Medicaid patients could sort across states in ways correlated with their Medicaid policies.

\subsubsection{Movers}

Following Molitor (2018), who uses physician movers, and other mover designs in labor and health economics (Abowd et al., 1999; Finkelstein et al., 2016; Hull, 2018), we examine the impact of a physician's move between states with different payment rates and billing difficulty. Consider physician $i$ who moves from state $s$ to $s^{\prime}$.

We define $\Delta \ln \mathrm{Fee}_{i} \equiv \widehat{\xi}_{s^{\prime}, \text { Medicaid }}-\widehat{\xi}_{s, \text { Medicaid }}$ as the difference between the $\log (\pi)$ indices in the pre-move and post-move states' Medicaid programs. Similarly, $\Delta \tau_{i} \equiv \widehat{\psi}_{s^{\prime}, \text { Medicaid }}-$ $\widehat{\psi}_{s, \text { Medicaid }}$ is the difference in the $\tau$ index for Medicaid before and after the move. Under the usual assumption that the timing and the origin-destination pair of a physician's cross-state move is independent of other shocks affecting her willingness to treat Medicaid patients, we use these changes to estimate the effect of both fees and CIP on the decision to accept Medicaid patients, while controlling for time-invariant physician unobservables.

Using data for years indexed by $t$ around physician $i$ 's move, we estimate the following regression at the physician-year level:

$$
Y_{i, t}=\beta \Delta \ln \mathrm{Fee}_{i} \cdot \mathbb{1}_{\mathrm{Post}_{i, t}}+\gamma \Delta \tau_{i} \cdot \mathbb{1}_{\text {Post }_{i, t}}+\eta_{i} \cdot \mathbb{1}_{i}+\phi \operatorname{Controls}_{i, t}+\epsilon_{i, t}
$$

The dependent variable $Y_{i, t}$ is a binary indicator for whether the physician reports accepting Medicaid patients. The key controls here are individual physician fixed effects $\eta_{i}$. This strategy identifies the coefficients $\beta$ and $\gamma$ exclusively based on physicians who move. The key moment is the difference in those physicians' post- and pre-move Medicaid acceptance decisions, and how that difference varies with differences in the states' policies.

To visualize the time trends in these results, we begin by estimating a dynamic event 
study version of equation (11), namely:

$$
Y_{i, t}=\sum_{\zeta \neq 0} \beta_{\zeta} \Delta \ln \mathrm{Fee}_{i} \cdot \mathbb{1}_{\zeta}+\sum_{\zeta \neq 0} \gamma_{\zeta} \cdot \Delta \tau_{i} \cdot \mathbb{1}_{\zeta}+\eta_{i} \cdot \mathbb{1}_{i}+\epsilon_{i, t}
$$

where $\zeta$ denotes the year relative to that in which the physician moved.

\subsubsection{Cross-State Groups}

The second strategy uses physician groups that span state boundaries. This encompasses longer-term decisions that a practice makes, such as specific location choice, hiring appropriate staff, and marketing to the target population. So these estimates can be thought of as responses implemented over a longer time horizon than those estimated by the movers strategy. Moreover, the decision maker is the group, rather than the individual physician.

Using the cross-state groups, we introduce practice group fixed effects into a physicianlevel regression of Medicaid acceptance on Medicaid fee and CIP indices:

$$
Y_{i, t}=\beta \widehat{\xi}_{s(i), \text { Medicaid }}+\gamma \widehat{\psi}_{s(i), \text { Medicaid }}+\vartheta_{g} \cdot \mathbb{1}_{g(i)}+\eta \cdot \mathbb{1}_{t}+\phi \text { Controls }_{i, t}+\epsilon_{i, t} .
$$

The dependent variable is the same as in regression (11), a binary indicator for whether the physician reports accepting Medicaid patients. The key controls are fixed effects $\mathbb{1}_{g(i)}$ for each physician group, defined based on the practice's tax identifier reported in MD-PPAS. Given these fixed effects, we identify $\beta$ and $\gamma$ off of differences in Medicaid acceptance among physicians within the same practice.

\subsubsection{Instrumenting for $\tau$ Indices Using Denial Indices}

We measure CIP as a share $\tau_{j}$ of claim value $\pi$, according to equation (2), and this $\tau_{j}$ share is our dependent variable when constructing the CIP index, $\widehat{\psi}_{s, k}$. So any measurement error in $\pi$ could bias estimation based on $\widehat{\psi}_{s, k}$ : measurement error in $\pi$ would enter positively into

the fee index $\widehat{\xi}_{s, k}$ and negatively into the CIP index $\widehat{\psi}_{s, k}$, potentially inducing a spurious 
negative correlation between their coefficients $\hat{\gamma}$ and $\hat{\beta}$. We address this by using the denialonly index $\widehat{\psi}_{s, k}^{D}$ from equation (7) as an instrument for the overall CIP index $\widehat{\psi}_{s, k}$. As this index is based only on an indicator variable for claim denial, it does not contain the same measurement error that could appear in $\widehat{\xi}_{s, k}$. The denial-only index $\widehat{\psi}_{s, k}^{D}$ strongly predicts the full CIP index $\widehat{\psi}_{s, k}$, as we show in Appendix Table A.5.

To use this instrument, we define $\Delta$ Denial $_{i}=\widehat{\psi}_{s^{\prime}, \text { Medicaid }}^{D}-\widehat{\psi}_{s, \text { Medicaid }}^{D}$ analogously to $\Delta \tau_{i}$, and estimate the first-stage equation

$$
\Delta \tau_{i} \cdot \mathbb{1}_{\text {Post }_{i, t}}=\alpha_{1} \Delta \ln \mathrm{Fee}_{i} \cdot \mathbb{1}_{\text {Post }_{i, t}}+\alpha_{2} \Delta \text { Denial }_{i} \cdot \mathbb{1}_{\text {Post }_{i, t}}+\eta_{i} \cdot \mathbb{1}_{i}+\phi \text { Controls }_{i, t}+\nu_{i, t} .
$$

We then replace $\Delta \tau_{i} \cdot \mathbb{1}_{\text {Post }_{i, t}}$ with the fitted values from (14) when estimating equation (11). We use an analogous 2SLS approach with the cross-state groups strategy.

\subsection{The Effect of Billing Hurdles on Medicaid Acceptance}

Figure 7 shows physicians' responses to fees and CIP around a move. Panel (a) plots $\hat{\beta}_{\zeta}$, the response to moving to a state with higher fees, while Panel (b) shows $\hat{\gamma}_{\zeta}$, the response to moving to a state with higher $\tau$. The coefficients and confidence intervals shown come from 2SLS estimates of equation (12), when instrumenting for $\Delta \tau_{i}$ with $\Delta$ Denial $_{i}$.

The pre-move trends in both panels are flat and close to zero. Prior to the physician's move, we see no relationship between the upcoming changes in fees or CIP and physicians' Medicaid acceptance decisions. After the move, we see clear positive coefficients for fees and negative for CIP. Higher $\pi$ increase the probability of Medicaid acceptance, while a higher $\tau$ reduces the probability. We discuss the magnitudes below, but for now simply note that the response is prompt and significant. The point estimates for fees increase over time, but are not precise enough to rule out a constant effect in years 1 through 4 after the move.

Table 6 shows estimates of equation (11), which pools the pre-move and post-move years and estimates a single coefficient on each index. Column 1 shows the OLS estimates using indices from equation (6) (with no selection correction). Column 2 instruments for $\Delta \tau_{i}$ with 
$\Delta$ Denial $_{i}$ as described in Section 4.2.3 above. Columns 3 and 4 are analogous, but use the $\tau$ index estimated with a Heckman selection correction rather than physician fixed effects. ${ }^{31}$

To interpret our results, the coefficient on log fees shows the effect of a 1 log point change in Medicaid rates on the probability of accepting Medicaid patients. For instance, the fee coefficient in column 1 means that a 0.1 increase in log fees (approximately 10 percent) leads to a 0.3 percentage point increase in physicians' propensity to accept Medicaid. The coefficient on $\Delta \tau$ multiplies a share coefficient, so a 10 percentage point increase in $\tau$ reduces the probability of accepting Medicaid patients by 0.8 percentage points. The 95 percent confidence interval around this estimate ranges from 0.3 to 1.3 percentage points.

To put these magnitudes in context, we compare a one-standard-deviation change in each key variable. The $\log (\pi)$ index has a cross-state standard deviation of 0.2 , while the $\tau$ index has a standard deviation of 0.11 (from Supplementary Appendix Table S.3). Using the estimates from column 2 of Table 6, moving to a state with one standard deviation higher fees increases the probability of accepting Medicaid patients by 0.6 percentage points, while moving to a state with one standard deviation higher CIP share reduces the probability by 0.8 percentage points. While these estimates - especially the impact of fees - have substantial uncertainty, our main takeaway is that CIP is just as important for understanding the variation in physicians' willingness to treat Medicaid patients as reimbursement rates are.

Correcting the $\tau$ index for non-random selection of visits slightly increases our estimated effect of billing hurdles on Medicaid acceptance. The impact of instrumenting for $\Delta \tau$ with the index of denial probability is even larger: the estimated coefficient on the CIP share shown in Column 4 of Table 6 is $-0.078,12$ percent larger than the OLS estimates.

Table 7 reports the results from our second strategy, exploiting variation in Medicaid acceptance across groups that cross state boundaries. We obtain slightly higher coefficients, as might be expected from longer-run responses. Indeed, the coefficients around 0.1 on $\log$ fees are very similar to the point estimate for year 4 after the move from Figure 7a. This

\footnotetext{
${ }^{31}$ Columns 3 and 4 still have physician fixed effects in the movers regression, just not in estimating the $\psi_{s, k}$ indices used to construct $\Delta \tau$.
} 
coefficient implies that physicians in a state with one standard deviation higher Medicaid reimbursements are around 2 percentage points more likely to accept Medicaid patients. Physicians in a state with one standard deviation higher CIP are 2 (based on column 3) to 2.8 (based on column 4) percentage points less likely to accept Medicaid patients. CIP is again just as important as reimbursements.

The Supplementary Appendix contains versions of Tables 6 and 7 incorporating a variety of robustness checks. First, we consider alternative constructions of the $\log (\pi)$ and $\tau$ indices, including - among others-PCP- vs. specialist-specific indices, indices that do not include resubmission costs in computing CIP, indices that are weighted by fees for $\tau$, and by RVUs for $\pi$. Second, we extend our estimating sample to physicians who do not accept Medicare. Third, we show results when distinguishing between Medicaid MCO and Medicaid FFS in the model, and controlling for the Medicaid MCO share in the regressions. We also include controls for the average commercial fees in a state, and consider a version of Table 7 which includes group-year fixed effects instead of group and year fixed effects separately. Our results remain robust and quantitatively similar across these specifications.

To summarize, these results demonstrate the profound importance of administrative hassles for Medicaid patients' access to care. Physicians appear to treat higher CIP just like they do lower fees: a loss in expected revenue that makes them reluctant to treat lower-income Americans. This is true both qualitatively and quantitatively - their behavioral responses to a given percentage change in net revenue are similar whether the change comes through fees or CIP. This highlights an important new dimension of health insurance that has been largely overlooked in policy discussions.

\section{Welfare: Policy Counterfactuals and Limitations}

\subsection{Increases in Fees vs. Reductions in Denials}

Our results introduce a new channel through which payers - particularly Medicaid - directly affect expected profitability of patients, thus impacting physicians' supply of care. We see 
that lowering CIP increases physicians' propensity to accept Medicaid patients in the same way that an increase in the reimbursement rate does.

In this section, we study the effect of changes in denial probabilities $(d)$ and changes in fees $(\pi)$ on CIP $(\tau)$, revenue collected per visit, and propensity to accept Medicaid. Policymakers and Medicaid administrators don't directly control $\tau$, as they can't choose which claims physicians resubmit. So instead of treating $\tau$ as a policy parameter, we assume payers set the denial frequency. Physicians adjust their resubmission choices optimally in response to the fees and denial probabilities they face. This analysis combines our model of optimal resubmission decisions with the estimated effects of $\tau$ and $\pi$ on Medicaid acceptance. ${ }^{32}$

First, we use the estimated resubmission costs from Section 3 to solve for the optimal resubmission strategy. We begin with the joint distribution of fees and denial probabilities across visits, denoted $F(\pi, d)$. For any value $(\pi, d)$, we use our model estimates to calculate each visit's CIP. ${ }^{33}$ Given any distribution $F(\pi, d)$, we denote the average CIP share as $\bar{\tau}(F(\pi, d))$, since it depends on the distribution $F()$. Supplementary Appendix Figure S.3 shows this $\bar{\tau}$ function. We then use this $\bar{\tau}(F(\pi, d))$ together with the new values of $\pi$ and $d$ to compute two objects. First, we compute the change in spending at $(\pi, d)$, accounting for physicians' changing resubmission decisions as described in footnote 32. Second, we use our Medicaid acceptance estimates from Section 4.2 .1 to identify the points $(\pi, d)$, which induce values of $\bar{\tau}(F(\pi, d))$ that hold physicians' Medicaid acceptance rate constant.

Figure 8 summarizes the results. The horizontal axis shows fee changes ranging from

\footnotetext{
${ }^{32}$ When holding $\pi$ constant, reducing the share of claims denied affects $\tau$ : the initial denied amounts are lower, and physicians change their resubmission decisions in light of the higher chance of receiving payments. When holding denial probability constant, changes to $\pi$ also alter $\tau$ : the amounts at stake are different, so physicians change their resubmission decisions. The denominator in equation (2) defining $\tau$ is also different.

${ }^{33}$ We simplify our calculations by considering the decision to resubmit or not the entire claim, ignoring differences between line items (more than half of the observations in our data include a single line). For a visit with given values of $(\pi, d)$ the physician resubmits a claim if$$
\beta\left(\pi(1-d)+d \mathcal{V}^{\star}(\pi, d)-C\right) \geq 0,
$$

where $\mathcal{V}^{\star}(\pi, d)$ solves the corresponding Bellman equation

$$
\mathcal{V}^{\star}(\pi, d)=\max \left\{0, \beta\left(\pi(1-d)+d \mathcal{V}^{\star}(\pi, d)-C\right)\right\} \text {. }
$$


$-20 \%$ to $+20 \%$. The vertical axis shows changes in the denial probability from $-30 \%$ to $+30 \%$. There are two types of level curves: first, the dashed lines show the changes in pervisit Medicaid payments to physicians in response to changes in fees and denial probabilities. For example, a $10 \%$ decrease in fees accompanied by a $20 \%$ decrease in denial probabilities would reduce per-visit spending by an average of $\$ 10$. Aggregating this across all Medicaid physician visits nationally adds up to $\$ 2$ billion per year. ${ }^{34}$

The solid line is a level curve that holds constant the probability physicians accept Medicaid. While our Medicaid acceptance regressions from Section 4.2.1 have substantial confidence intervals, we plot a single curve based on the point estimates. Since this curve runs through the same point $(-10 \%,-20 \%)$ discussed above, these $\$ 10$ savings could be achieved holding constant physicians' Medicaid acceptance. This specific change is only one of the (infinitely) many examples of "deviations" from the status-quo that could generate savings while maintaining the same physician access. Alternatively, the savings could be used to increase reimbursements and thus expand physician access.

Another way to view these results is as a lower bound on the value Medicaid must get from denials for its current policy to be justified. If the current denial rate helps Medicaid reduce fraud or wasteful care by at least $\$ 10$ per visit, the proposed deviation to $(-10 \%$, $-20 \%$ ) would not be efficient. Figure 8 shows the incremental denials must be worth at least $\$ 10$ per visit-relative to a denial rate $20 \%$ lower-for the current policy to be justified.

This section illustrates our findings' first-order policy implications. Beyond fees, market sponsors affect Medicaid acceptance and spending by determining how physicians interact with insurers. We have estimated the potential savings from changing this process. Given the magnitude of potential gains, the caveats, limitations, and unmodeled reasons for denials would need to also be economically large to justify the observed denial rate.

\footnotetext{
${ }^{34}$ As of August 2022 there are 83 million Medicaid enrollees (https://www.medicaid.gov/medicaid/ program-information/medicaid-and-chip-enrollment-data/report-highlights/index.html; accessed on December 13, 2022), and the average number of annual doctor visits is 2.4 (authors' calculations using the Medical Expenditure Panel Survey, obtained from https://www.meps.ahrq.gov/mepsweb/).
} 


\subsection{Caveats and Limitations}

The results in this paper highlight an important friction in healthcare markets, but it is important to clarify what they do and don't demonstrate. First, billing hassles could have benefits we don't measure, such as deterring wasteful care or detecting fraud. Future work should investigate these effects in Medicaid, as recent work has done in other contexts in Medicare (Shi, 2022; Brot-Goldberg et al., 2022; Eliason et al., 2021). Even if there are offsetting benefits, the administrative costs are high and deter physicians from participating in Medicaid. Unless these marginal physicians offer particularly inefficient or fraudulent care - another important question for future work - shrinking Medicaid patients' choice set is a concern for those interested in the quality of Medicaid or equity in healthcare access.

Second, we only consider one type of administrative hassle: the billing process after care is provided. We do not incorporate the costs of preparing initial submissions, or the fixed costs of setting up a billing office or contracting with outside billing firms. Physicians' other administrative burdens include licensure and registration with insurers, establishing payment contracts (Clemens, Gottlieb and Molnár, 2017), and obtaining preauthorization for care (Brot-Goldberg et al., 2022). Patients face their own burdens, including signing up for insurance and finding providers whose care their insurer covers (Handel and Kolstad, 2015; Brot-Goldberg, Layton, Vabson and Wang, 2021). Identifying a broader concept of administrative dysfunction may yield opportunities to make healthcare markets more efficient. ${ }^{35}$ We also exclude the insurer's own billing costs. Each interaction we observe from the physician's end has a corresponding cost for the insurer who processes it. Our cost estimates are undoubtedly a lower bound.

Third, our counterfactual analysis in the previous subsection only considers the patient acceptance response margin. States, insurers, and physicians may have other margins of

\footnotetext{
${ }^{35}$ Some current missed opportunities include failure to adopt cheap, effective technologies (Skinner and Staiger, 2005, 2015); overuse of low-value care (Schwartz et al., 2014; Alsan et al., 2015); omitting simple procedures that would improve efficiency of care allocation; and failing to maximize insurance coverage among populations that benefit (Hendren and Sprung-Keyser, 2020; Goldin, Lurie and McCubbin, 2021; Miller, Johnson and Wherry, 2021).
} 
response to use when payment rates change: Physicians can change their efforts to recruit Medicaid and non-Medicaid patients, or try to cream-skim patients who are less costly to treat. Insurers can adjust coverage rules or preauthorization requirements, and states can change Medicaid enrollment numbers. While Appendix A.4 finds no evidence that denial rates impact care patterns conditional on patient characteristics, there could be some types of patients we don't identify whose care is affected.

Finally, we do not consider the incentives of states or insurers. Our estimates of physicians' behavior do not account for strategic behavior on the other side of this negotiation. States, and the Medicaid insurers they contract with, are relevant players whose decisions should also enter into positive and normative analysis of this market.

\section{Conclusion}

This paper examines the economics of one of the largest sources of administrative problems in healthcare: how physicians and insurers haggle over payments for medical care. We find evidence that these payments are frequently incomplete, and we estimate that physicians incur large costs from this incompleteness - especially when submitting bills to Medicaid.

We show that these costs depress doctors' supply of care to Medicaid patients. Their willingness to participate in Medicaid responds just as much to billing difficulty as to the reimbursement rate. Our framework identifies deviations in Medicaid fees and claim denials that could save money while maintaining patients' access to physicians.

These findings demonstrate the value of well-functioning business operations in healthcare. Difficulty with payment collection meaningfully impacts firms' willingness to engage in markets. In the case of a major government healthcare program, this hassle compounds the effect of low payment rates to deter physicians from treating publicly insured patients.

\section{References}

Abowd, John M., Francis Kramarz, and David N. Margolis, "High Wage Workers and High Wage Firms," Econometrica, 1999, 67 (2), 251-333. 
Ahmed, Waqas, Adnan Haider, and Javed Iqbal, "Estimation of discount factor (beta) and coefficient of relative risk aversion (gamma) in selected countries," 2012.

Alexander, Diane and Molly Schnell, "The impacts of physician payments on patient access, use, and health," Working Paper 26095, National Bureau of Economic Research July 2019.

Allen, Marshall, "We Asked Prosecutors if Health Insurance Companies Care About Fraud. They Laughed at Us.," ProPublica, September 10 2019. Available online at https://www.propublica.org/article/ we-asked-prosecutors-if-health-insurance-companies-care-about-fraud-they-laughed-at-u

Alsan, Marcella, Nancy Morden, Joshua D. Gottlieb, Weiping Zhou, and Jonathan Skinner, "Antibiotic Use in Cold and Flu Season and Prescribing Quality: A Retrospective Cohort Study," Medical Care, December 2015, 53 (12), 1066-1071.

Backus, Matthew, Thomas Blake, and Steven Tadelis, "On the empirical content of cheap-talk signaling: An application to bargaining," Journal of Political Economy, 2019, 127 (4), 1599-1628.

_ , _ , Brad Larsen, and Steven Tadelis, "Sequential bargaining in the field: Evidence from millions of online bargaining interactions," Quarterly Journal of Economics, 2020, 135 (3), 1319-1361.

Bagwell, Kyle, Robert W Staiger, and Ali Yurukoglu, "Multilateral trade bargaining: A first look at the GATT bargaining records," American Economic Journal: Applied Economics, 2020, 12 (3), 72-105.

Besley, Timothy and Stephen Coate, "Workfare versus Welfare: Incentive Arguments for Work Requirements in Poverty-Alleviation Programs," American Economic Review, 1992, 82 (1), 249-261.

Bloom, Nicholas, Carol Propper, Stephan Seiler, and John Van Reenen, "The impact of competition on management quality: evidence from public hospitals," The Review of Economic Studies, 2015, 82 (2), 457-489.

Bound, John and Richard V. Burkhauser, "Economic analysis of transfer programs targeted on people with disabilities," in "Handbook of Labor Economics," Vol. 3 of Handbook of Labor Economics, Elsevier, 1999, chapter 51, pp. 3417 - 3528.

Brot-Goldberg, Zarek C, Timothy Layton, Boris Vabson, and Adelina Yanyue Wang, "The Behavioral Foundations of Default Effects: Theory and Evidence from Medicare Part D," Technical Report, National Bureau of Economic Research 2021.

Brot-Goldberg, Zarek, Samantha Burn, Timothy Layton, and Boris Vabson, "Rationing Medicine Through Bureaucracy: Authorization Restrictions in Medicare," September 2022. University of Chicago, mimeo. Available online at https://zarekcb.github . io/PriorAuth_Web.pdf (accessed September 15, 2022). 
Bundorf, M Kate, Jonathan Levin, and Neale Mahoney, "Pricing and welfare in health plan choice," American Economic Review, 2012, 102 (7), 3214-48.

Candon, Molly, Stephen Zuckerman, Douglas Wissoker, Brendan Saloner, Genevieve M. Kenney, Karin Rhodes, and Daniel Polsky, "Declining Medicaid Fees and Primary Care Appointment Availability for New Medicaid Patients," JAMA Internal Medicine, 01 2018, 178 (1), 145-146.

CAQH, "2020 CAQH INDEX: Closing the Gap: The Industry Continues to Improve, But Opportunities for Automation Remain," 2020. Available online at https://www.caqh. org/sites/default/files/explorations/index/2020-caqh-index.pdf.

Casalino, Lawrence P, Sean Nicholson, David N Gans, Terry Hammons, Dante Morra, Theodore Karrison, and Wendy Levinson, "What Does It Cost Physician Practices To Interact With Health Insurance Plans? A new way of looking at administrative costs - one key point of comparison in debating public and private health reform approaches.," Health Affairs, 2009, 28 (Suppl1), w533-w543.

Centers for Medicare and Medicaid Services, "The Nation’s Health Dollar $(\$ 3.8$ Trillion), Calendar Year 2019: Where It Came From," 2019. Available online at https://web.archive.org/web/20210216022424/https://www.cms.gov/files/ document/nations-health-dollar-where-it-came-where-it-went.pdf (accessed September 16, 2022).

_ , "National Health Expenditures 2020 Highlights," 2020.

Cicala, Steve, Ethan MJ Lieber, and Victoria Marone, "Regulating Markups in US Health Insurance," American Economic Journal: Applied Economics, 2019, 11 (4), 71-104.

Clemens, Jeffrey and Joshua D. Gottlieb, "Do Physicians' Financial Incentives Affect Treatment Patterns and Patient Health?," American Economic Review, April 2014, 104 (4), 1320-1349.

_ and _ , "In the Shadow of a Giant: Medicare's Influence on Private Payment Systems," Journal of Political Economy, February 2017, 125 (1), 1-39.

_, _, and Tímea Laura Molnár, "Do Health Insurers Innovate? Evidence From the Anatomy of Physician Payments," Journal of Health Economics, September 2017, 55, $153-167$.

Cooper, Zack, Stuart V Craig, Martin Gaynor, and John Van Reenen, "The Price Ain't Right? Hospital Prices and Health Spending on the Privately Insured," Quarterly Journal of Economics, 09 2018, 134 (1), 51-107.

Crocker, Keith J and John Morgan, "Is honesty the best policy? Curtailing insurance fraud through optimal incentive contracts," Journal of Political Economy, 1998, 106 (2), $355-375$. 
- and Sharon Tennyson, "Insurance fraud and optimal claims settlement strategies," The Journal of Law and Economics, 2002, 45 (2), 469-507.

Cunningham, Peter J. and Ann S. O'Malley, "Do Reimbursement Delays Discourage Medicaid Participation By Physicians?," Health Affairs, 2008, 27 (Supplement 1), w17w28.

Currie, Janet, Jeffrey Grogger, Gary Burtless, and Robert F. Schoeni, "Explaining Recent Declines in Food Stamp Program Participation," Brookings-Wharton Papers on Urban Affairs, 2001, pp. 203-244.

Curto, Vilsa, Liran Einav, Jonathan Levin, and Jay Bhattacharya, "Can Health Insurance Competition Work? Evidence from Medicare Advantage," Journal of Political Economy, 2021, 129 (2), 570-606.

Cutler, David M., "Reducing Administrative Costs in U.S. Health Care," The Hamilton Project Policy Proposal 2020-09, Brookings Institution March 2020. Available online at https://www . brookings . edu/wp-content/uploads/2020/03/Cutler_PP_LO.pdf.

- and Dan P. Ly, "The (Paper)Work of Medicine: Understanding International Medical Costs," Journal of Economic Perspectives, 2011, 25 (2), 3-25.

Deshpande, Manasi and Yue $\mathbf{L i}$, "Who is screened out? application costs and the targeting of disability programs," American Economic Journal: Economic Policy, 2019, $11(4), 213-48$.

Dionne, Georges, Florence Giuliano, and Pierre Picard, "Optimal auditing with scoring: Theory and application to insurance fraud," Management Science, 2009, 55 (1), $58-70$.

Dranove, David, Christopher Ody, and Amanda Starc, "A Dose of Managed Care: Controlling Drug Spending in Medicaid," American Economic Journal: Applied Economics, 2021, 13 (1), 170-97.

Dunn, Abe and Adam Hale Shapiro, "Physician competition and the provision of care: evidence from heart attacks," American Journal of Health Economics, 2018, 4 (2), 226261.

Dynarski, Susan and Judith E. Scott-Clayton, "The Cost of Complexity in Federal Student Aid: Lessons From Optimal Tax Theory and Behavioral Economics," National Tax Journal, 2006, 59 (2), 319-56.

Einav, Liran, Amy Finkelstein, and Mark R Cullen, "Estimating welfare in insurance markets using variation in prices," Quarterly Journal of Economics, 2010, 125 (3), 877921.

Eliason, Paul, Riley League, Jetson Leder-Luis, Ryan C. McDevitt, and James W. Roberts, "Ambulance Taxis: The Impact of Regulation and Litigation on Health Care Fraud," Working Paper No. 29491, National Bureau of Economic Research November 2021. 
Ericson, Keith M Marzilli and Amanda Starc, "Pricing regulation and imperfect competition on the massachusetts health insurance exchange," Review of Economics and Statistics, 2015, 97 (3), 667-682.

Finkelstein, Amy and Matthew J Notowidigdo, "Take-Up and Targeting: Experimental Evidence from SNAP," Quarterly Journal of Economics, 05 2019, 134 (3), 1505-1556.

_, Matthew Gentzkow, and Heidi Williams, "Sources of Geographic Variation in Health Care: Evidence From Patient Migration," Quarterly Journal of Economics, 07 2016, 131 (4), 1681-1726.

Fudenberg, Drew, David K Levine, and Jean Tirole, "Sequential bargaining with many buyers," Working Paper No. 366 February 1985.

Gennaioli, Nicola, Rafael La Porta, Florencio Lopez de Silanes, and Andrei Shleifer, "Trust and Insurance Contracts," Working Paper 27189, National Bureau of Economic Research May 2020.

Goldin, Jacob, Ithai Z Lurie, and Janet McCubbin, "Health insurance and mortality: Experimental evidence from taxpayer outreach," Quarterly Journal of Economics, 2021, 136 (1), 1-49.

Gottlieb, Joshua D., Adam Hale Shapiro, and Abe Dunn, "The Complexity Of Billing And Paying For Physician Care," Health Affairs, April 2018, 37 (4), 619-626.

_ , Maria Polyakova, Kevin Rinz, Hugh Shiplett, and Victoria Udalova, "Who Values Human Capitalists' Human Capital? The Earnings and Labor Supply of U.S. Physicians," June 2021. University of Chicago, mimeo.

Gowrisankaran, Gautam, Keith A Joiner, and Jianjing Lin, "How Do Hospitals Respond to Payment Incentives?," Working Paper 26455, National Bureau of Economic Research November 2019.

Gruber, Jon, John Kim, and Dina Mayzlin, "Physician Fees and Procedure Intensity: the Case of Cesarean Delivery," Journal of Health Economics, August 1999, 18 (4), 473490.

Handel, Benjamin R and Jonathan T Kolstad, "Health insurance for" humans": Information frictions, plan choice, and consumer welfare," American Economic Review, 2015, 105 (8), 2449-2500.

Heckman, James J, "Sample selection bias as a specification error," Econometrica: Journal of the econometric society, 1979, pp. 153-161.

Hendren, Nathaniel and Ben Sprung-Keyser, "A unified welfare analysis of government policies," Quarterly Journal of Economics, 2020, 135 (3), 1209-1318.

Hernandez-Arenaz, Iñigo and Nagore Iriberri, "Women ask for less (only from men): Evidence from bargaining in the field," Journal of Economic Behavior \& Organization, 2018, 152, 192-214. 
Hotz, V Joseph and Robert A Miller, "Conditional choice probabilities and the estimation of dynamic models," The Review of Economic Studies, 1993, 60 (3), 497-529.

Hull, Peter, "Estimating Treatment Effects in Mover Designs," Technical Report 1804.06721, arXiv.org April 2018.

Jindal, Pranav and Peter Newberry, "Price negotiations and bargaining costs," Technical Report, Mimeo, Pennsylvania State University. Available online at https://citeseerx.ist.psu.edu/viewdoc/download?doi=10.1.1.709.2075\&rep= rep1\&type=pdf. April 2015.

Keniston, Daniel, "Bargaining and welfare: A dynamic structural analysis of the autorickshaw market," Unpublished manuscript, Yale University, 2011.

Larsen, Bradley, "The efficiency of real-world bargaining: Evidence from wholesale usedauto auctions," Working Paper No. 20431, National Bureau of Economic Research 2014.

Long, Sharon K., "Physicians May Need More Than Higher Reimbursements To Expand Medicaid Participation: Findings From Washington State," Health Affairs, 2013, 32 (9), 1560-1567. PMID: 24019360.

Ly, Dan P and Sherry A Glied, "The impact of managed care contracting on physicians," Journal of General Internal Medicine, 2014, 29 (1), 237-242.

Miller, Sarah, Norman Johnson, and Laura R Wherry, "Medicaid and mortality: new evidence from linked survey and administrative data," Working Paper 26081, National Bureau of Economic Research January 2021.

Molitor, David, "The Evolution of Physician Practice Styles: Evidence from Cardiologist Migration," American Economic Journal: Economic Policy, February 2018, 10 (1), 32656.

Morra, Dante, Sean Nicholson, Wendy Levinson, David N Gans, Terry Hammons, and Lawrence P Casalino, "US physician practices versus Canadians: spending nearly four times as much money interacting with payers," Health Affairs, 2011, 30 (8), $1443-1450$.

Nichols, Albert L. and Richard J. Zeckhauser, "Targeting Transfers through Restrictions on Recipients," American Economic Review, 1982, 72 (2), 372-377.

Nichols, Donald A., Eugene Smolensky, and Thorwald N. Tideman, "Discrimination by Waiting Time in Merit Goods," American Economic Review, 1971, 61 (3), $312-323$.

Oostrom, Tamar, Liran Einav, and Amy Finkelstein, "Outpatient office wait times and quality of care for Medicaid patients," Health Affairs, 2017, 36 (5), 826-832. 
Polsky, Daniel, Michael Richards, Simon Basseyn, Douglas Wissoker, Genevieve M. Kenney, Stephen Zuckerman, and Karin V. Rhodes, "Appointment Availability after Increases in Medicaid Payments for Primary Care," New England Journal of Medicine, 2015, 372 (6), 537-545.

Pozen, Alexis and David M Cutler, "Medical spending differences in the United States and Canada: the role of prices, procedures, and administrative expenses," INQUIRY: The Journal of Health Care Organization, Provision, and Financing, 2010, 47 (2), 124-134.

Reinhardt, Uwe E., "The Pricing Of U.S. Hospital Services: Chaos Behind A Veil Of Secrecy," Health Affairs, 2006, 25 (1), 57-69. PMID: 16403745.

Schwartz, Aaron L, Bruce E Landon, Adam G Elshaug, Michael E Chernew, and J Michael McWilliams, "Measuring low-value care in Medicare," JAMA internal medicine, 2014, 174 (7), 1067-1076.

Shepard, Mark, "Hospital network competition and adverse selection: evidence from the Massachusetts health insurance exchange," American Economic Review, 2022, 112 (2), $578-615$.

Shi, Maggie, "The Costs and Benefits of Monitoring Providers: Evidence from Medicare Audits," April 2022. Columbia University, mimeo. Available online at https://mshi311. github.io/website/Shi_MedicareAudits_2022_04_22.pdf (accessed August 24, 2022).

Skinner, Jonathan and Douglas Staiger, "Technology adoption from hybrid corn to beta blockers," Technical Report, National Bureau of Economic Research 2005.

_ and _ , "Technology diffusion and productivity growth in health care," Review of Economics and Statistics, 2015, 97 (5), 951-964.

Sloan, Frank, Janet Mitchell, and Jerry Cromwell, "Physician participation in state Medicaid programs," Journal of Human Resources, 1978, pp. 211-245.

Tebaldi, Pietro, "Estimating equilibrium in health insurance exchanges: Price competition and subsidy design under the aca," Technical Report, National Bureau of Economic Research 2022.

Tirole, Jean, "Incomplete contracts: Where do we stand?," Econometrica, 1999, 67 (4), 741-781.

Tseng, Phillip, Robert S. Kaplan, Barak D. Richman, Mahek A. Shah, and Kevin A. Schulman, "Administrative Costs Associated With Physician Billing and Insurance-Related Activities at an Academic Health Care System," JAMA, 02 2018, 319 (7), 691-697.

Zwick, Eric, "The costs of corporate tax complexity," American Economic Journal: Economic Policy, 2021, 13 (2), 467-500. 
Table 1: Remittance Data Summary, Visit Level

\begin{tabular}{lccccc}
\hline & Mean & SD & 10th Percentile & 90th Percentile & Observations \\
\hline Initial claim value $(\$)$ & 155.12 & 401.58 & 29.21 & 240.00 & $81,392,495$ \\
Number of line items & 1.81 & 1.51 & 1.00 & 3.00 & $81,392,495$ \\
Number of submitted claims & 1.04 & 0.24 & 1.00 & 1.00 & $81,392,495$ \\
Some items denied $(0,1)$ & 0.07 & 0.25 & 0.00 & 0.00 & $81,392,495$ \\
Initial denied amount $(\$)$ & 9.39 & 115.60 & 0.00 & 0.00 & $81,392,495$ \\
Final denied amount $(\$)$ & 5.96 & 87.64 & 0.00 & 0.00 & $81,392,495$ \\
Medicare patient $(0,1)$ & 0.46 & 0.50 & 0.00 & 1.00 & $81,392,495$ \\
Medicaid patient $(0,1)$ & 0.08 & 0.26 & 0.00 & 0.00 & $81,392,495$ \\
Private patient $(0,1)$ & 0.47 & 0.50 & 0.00 & 1.00 & $81,392,495$ \\
\hline
\end{tabular}

Note: This table summarizes the remittance data at the visit level. See Section 2.2 and Appendix A.2 for details. All visits are included in all rows, so all moments are unconditional. This means denial amounts include zeros for all non-denied line items. 
Table 2: Claim Values and Denials by Insurer, Visit Level

\begin{tabular}{lccc}
\hline & Medicaid & Medicare & Commercial \\
\hline Initial claim value $(\$)$ & 101.78 & 135.47 & 182.84 \\
Some items denied $(0,1)$ & 0.242 & 0.067 & 0.041 \\
Initial denied amount $(\$)$ & 20.03 & 9.18 & 7.88 \\
Final denied amount $(\$)$ & 15.02 & 5.63 & 4.82 \\
Collected visit revenue $(\$)$ & 86.75 & 129.84 & 178.01 \\
Share of denied claims resubmitted: & & \\
Once & 0.342 & 0.617 & 0.603 \\
Twice & 0.066 & 0.065 & 0.048 \\
Three times & 0.021 & 0.018 & 0.013 \\
Four times & 0.009 & 0.005 & 0.005 \\
Five or more times & 0.004 & 0.002 & 0.002 \\
\hline
\end{tabular}

Note: This table reports averages across visits for each payer category. All visits are included in each average in the first five rows, so all averages are conditional only on the payer category. This means denial amounts include zeros for all non-denied line items. "Some items denied" takes value one if one or more line items within the claim are denied initial payment. The rows under "Share of denied claims resubmitted" are conditional on an initial denial. They summarize the number of iterations following this initial denial. For example, the value of 0.342 for Medicaid claims resubmitted once indicates that 34.2 percent of denied claims are resubmitted, while in the remaining 65.8 percent of cases physicians forego denied amounts. 
Table 3: Summary of Remittance Data Following Denials, Line Item Level

\begin{tabular}{lcccccc}
\hline & $\begin{array}{c}\text { Denial } \\
\text { Rate }\end{array}$ & $\begin{array}{c}\text { Share of } \\
\text { Denials }\end{array}$ & $\begin{array}{c}\text { Mean } \\
\text { Line Item Value }\end{array}$ & $\begin{array}{c}\text { Mean Pr. of } \\
\text { Resubmission }\end{array}$ & $\begin{array}{c}\text { Mean \# of } \\
\text { Resubmissions }\end{array}$ & $\begin{array}{c}\text { Mean } \\
\text { Recovery Rate }\end{array}$ \\
\hline Administrative & 0.057 & 0.247 & 53.68 & 0.39 & 0.51 & 0.58 \\
Contractual & 0.070 & 0.305 & 44.91 & 0.35 & 0.43 & 0.92 \\
Coverage & 0.055 & 0.240 & 57.03 & 0.25 & 0.34 & 0.32 \\
Duplicate & 0.010 & 0.043 & 60.14 & 0.19 & 0.24 & 0.14 \\
Information & 0.038 & 0.164 & 64.13 & 0.42 & 0.58 & 0.29 \\
& & \multicolumn{7}{c}{ Panel a: Medicaid } \\
Administrative & 0.010 & 0.163 & 89.66 & 0.57 & 0.66 & 0.94 \\
Contractual & 0.025 & 0.389 & 84.55 & 0.82 & 0.88 & 0.98 \\
Coverage & 0.014 & 0.226 & 83.00 & 0.39 & 0.49 & 0.34 \\
Duplicate & 0.007 & 0.116 & 82.87 & 0.46 & 0.57 & 0.45 \\
Information & 0.007 & 0.105 & 90.11 & 0.60 & 0.77 & 0.54 \\
& & \multicolumn{7}{c}{ Panel c: Commercial } & & 0.72 \\
Administrative & 0.005 & 0.138 & 103.29 & 0.26 & 0.31 & 0.99 \\
Contractual & 0.022 & 0.596 & 101.35 & 0.79 & 0.85 & 0.67 \\
Coverage & 0.003 & 0.077 & 124.55 & 0.43 & 0.52 & 0.20 \\
Duplicate & 0.004 & 0.104 & 103.86 & 0.22 & 0.27 & 0.43 \\
Information & 0.003 & 0.085 & 146.48 & 0.47 & 0.62 & \\
\hline
\end{tabular}

Note: This table reports averages across line items (procedures) for each payer category, distinguishing between reasons (categories) of denials. The first column summarizes the probability of a payment for a line item being denied, for each reason category and payer. The second column adds up to 100 within payer, showing the frequency of different reason categories across line items that are denied initial payment. The third column shows average values of line items denied across payers and reasons. The fourth column shows the probability that a line item is resubmitted after the initial denial. The fifth column shows the average number of resubmissions following the initial denial, while the last column shows the probability that the line item is ultimately reimbursed. 
Table 4: Physician Survey Summary

\begin{tabular}{lcc}
\hline & Mean & Observations \\
\hline Physician accepts: & & \\
Medicaid (0,1) & 0.720 & $3,688,970$ \\
Medicare (0,1) & 0.841 & $3,688,970$ \\
Medicaid | Doctor accepts Medicare & 0.803 & $3,102,638$ \\
Medicaid | Doctor does not accept Medicare & 0.288 & 586,332 \\
\hline Cross-state mover (0,1) & 0.011 & $3,688,970$ \\
Cross-state group (Tax ID; 0,1) & 0.273 & $3,688,970$ \\
\hline
\end{tabular}

Note: This table summarizes the SK\&A survey augmented with the MD-PPAS dataset at the physician-year level. The top panel includes a summary of the two indicators for whether a physician accepts Medicaid or Medicare, respectively. Rows 3 and 4, respectively, focus only on physicians accepting Medicare, and only on physicians not accepting Medicare. The bottom panel includes an indicator for physicians who move across states (relative to the prior year), and an indicator taking for whether the physician works in a group active across multiple states. 
Table 5: Estimates of Per-Visit CIP and $\tau$

\begin{tabular}{|c|c|c|c|c|c|}
\hline & $\begin{array}{c}\text { All } \\
\text { Phys. }\end{array}$ & $\begin{array}{c}\text { All } \\
\text { Phys. }\end{array}$ & $\begin{array}{c}\text { All } \\
\text { Phys. }\end{array}$ & $\begin{array}{l}\text { Small } \\
\text { Group }\end{array}$ & $\begin{array}{l}\text { Large } \\
\text { Group }\end{array}$ \\
\hline \multicolumn{6}{|c|}{ Panel a: Medicaid } \\
\hline Average $\tau$ & 0.141 & 0.174 & 0.176 & 0.183 & 0.174 \\
\hline Average CIP & 9.75 & 12.43 & 12.50 & 13.06 & 12.30 \\
\hline \multicolumn{6}{|c|}{ Panel b: Medicare } \\
\hline Average $\tau$ & 0.033 & 0.047 & 0.047 & 0.059 & 0.044 \\
\hline Average CIP & 2.66 & 3.94 & 3.93 & 4.97 & 3.60 \\
\hline \multicolumn{6}{|c|}{ Panel c: Commercial } \\
\hline Average $\tau$ & 0.019 & 0.024 & 0.024 & 0.031 & 0.023 \\
\hline Average CIP & 1.79 & 2.36 & 2.37 & 2.95 & 2.19 \\
\hline Resubmission cost & No & Yes & Yes & Yes & Yes \\
\hline Denial reason heterogeneity & No & No & Yes & Yes & Yes \\
\hline Practice size heterogeneity & No & No & No & Yes & Yes \\
\hline
\end{tabular}

Note: This table summarizes our estimates of CIP and $\tau$ across payers and across alternative model specifications. Column 1 corresponds to a model that ignores resubmission costs, Column 2 considers resubmission costs that do not vary across denial reasons, Column 3 allows resubmission costs to vary by reason, and Column 4 and 5 allows resubmission costs to vary by size of physician practice, distinguishing between 1-2 physicians, or larger. See Table A.4 for details on the estimates of the parameters in the resubmission cost function $\mu$. 
Table 6: Effect of CIP and Fees on Medicaid Acceptance: Movers Strategy

\begin{tabular}{lcccc}
\hline & \multicolumn{4}{c}{ Accept Medicaid Patients? } \\
\cline { 2 - 5 } & $(1)$ & $(2)$ & $(3)$ & $(4)$ \\
\hline Post-move $\times \Delta \tau$ index & $-0.0670^{* * *}$ & $-0.0773^{* * *}$ & $-0.0695^{* * *}$ & $-0.0779^{* * *}$ \\
& $(0.0218)$ & $(0.0249)$ & $(0.0189)$ & $(0.0245)$ \\
Post-move $\times \Delta \log \pi$ index & $0.0321^{* *}$ & $0.0311^{* *}$ & $0.0296^{* *}$ & $0.0285^{* *}$ \\
& $(0.0127)$ & $(0.0130)$ & $(0.0126)$ & $(0.0130)$ \\
\hline Estimator & OLS & 2 SLS & OLS & 2 SLS \\
Subsample Accepting Medicare & Yes & Yes & Yes & Yes \\
N. Physicians & 8,182 & 8,182 & 8,182 & 8,182 \\
N. Physicians-Years & 47,806 & 47,806 & 47,806 & 47,806 \\
Physician FE & Yes & Yes & Yes & Yes \\
Controls & Yes & Yes & Yes & Yes \\
\hline$\tau$ index: & & & & No \\
\multicolumn{1}{c}{ Selection Correction } & No & No & Yes & Yes \\
\hline
\end{tabular}

Note: This table shows the estimates of $\beta$ and $\gamma$ of equation (11). Standard errors are clustered at the state level. Each observation is a physician-year, including only physicians moving across states, from 3 years before the move through 4 years after. The sample is limited to physicians accepting Medicare (this is relaxed in the Supplementary Appendix). All specifications include physician fixed effects and control for the share of individuals in the county covered by Medicaid, the share of uninsured individual, the average Medicare HCC risk score, the number of physicians, the number of physicians per capita, unemployment, share white, population, share veterans, share below poverty, and median household income. Columns 1 and 3 are OLS estimates, while Columns 2 and 4 are 2SLS estimates instrumenting for $\Delta \tau_{i}$ with $\Delta$ Denial $_{i}$ as desribed in Section 4.2.3. Columns 1 and 2 use $\tau$ indices estimated with physician fixed effects, without selection correction. Columns 3 and 4 use $\tau$ indices estimated without physician fixed effects, with a selection correction. 
Table 7: Effect of CIP and Fees on Medicaid Acceptance: Group Strategy

\begin{tabular}{lcccc}
\hline & \multicolumn{4}{c}{ Accept Medicaid Patients? } \\
\cline { 2 - 5 } & $(1)$ & $(2)$ & $(3)$ & $(4)$ \\
\hline$\tau$ index & $-0.1291^{* * *}$ & $-0.1437^{* * *}$ & $-0.1014^{*}$ & $-0.1482^{* * *}$ \\
& $(0.0458)$ & $(0.0423)$ & $(0.0526)$ & $(0.0431)$ \\
$\log \pi$ index & $0.1157^{* * *}$ & $0.1142^{* * *}$ & $0.1170^{* * *}$ & $0.1116^{* * *}$ \\
& $(0.0201)$ & $(0.0203)$ & $(0.0212)$ & $(0.0212)$ \\
\hline Estimator & OLS & 2 SLS & OLS & 2 SLS \\
Subsample Accepting Medicare & Yes & Yes & Yes & Yes \\
N. Physicians & 232,590 & 232,590 & 232,590 & 232,590 \\
N. Physicians-Years & 807,599 & 807,599 & 807,599 & 807,599 \\
Group FE & Yes & Yes & Yes & Yes \\
Controls & Yes & Yes & Yes & Yes \\
\hline$\tau$ index: & & & & \\
\multicolumn{1}{c}{ Pelection Correction } & No & No & Yes & Yes \\
\hline
\end{tabular}

Note: This table shows the estimates of $\beta$ and $\gamma$ of equation (13). Standard errors are clustered at the state level. Each observation is a physician-year combination, the sample is restricted requiring that the physician accepts Medicare (this is relaxed in the Supplementary Appendix). All specifications include group fixed effects and control for the share of individuals in the county covered by Medicaid, the share of uninsured individual, the average Medicare HCC risk score, the number of physicians, the number of physicians per capita, unemployment, share white, population, share veterans, share below poverty, and median household income. Columns 1 and 3 are OLS estimates, while Columns 2 and 4 are 2SLS estimates instrumenting for $\Delta \tau_{i}$ with $\Delta$ Denial $_{i}$ as desribed in Section 4.2.3. Columns 1 and 2 use $\tau$ indices estimated with physician fixed effects, without selection correction. Columns 3 and 4 use $\tau$ indices estimated without physician fixed effects, with a selection correction. 
Figure 1: Overview of The Billing Process Underlying the Remittance Data

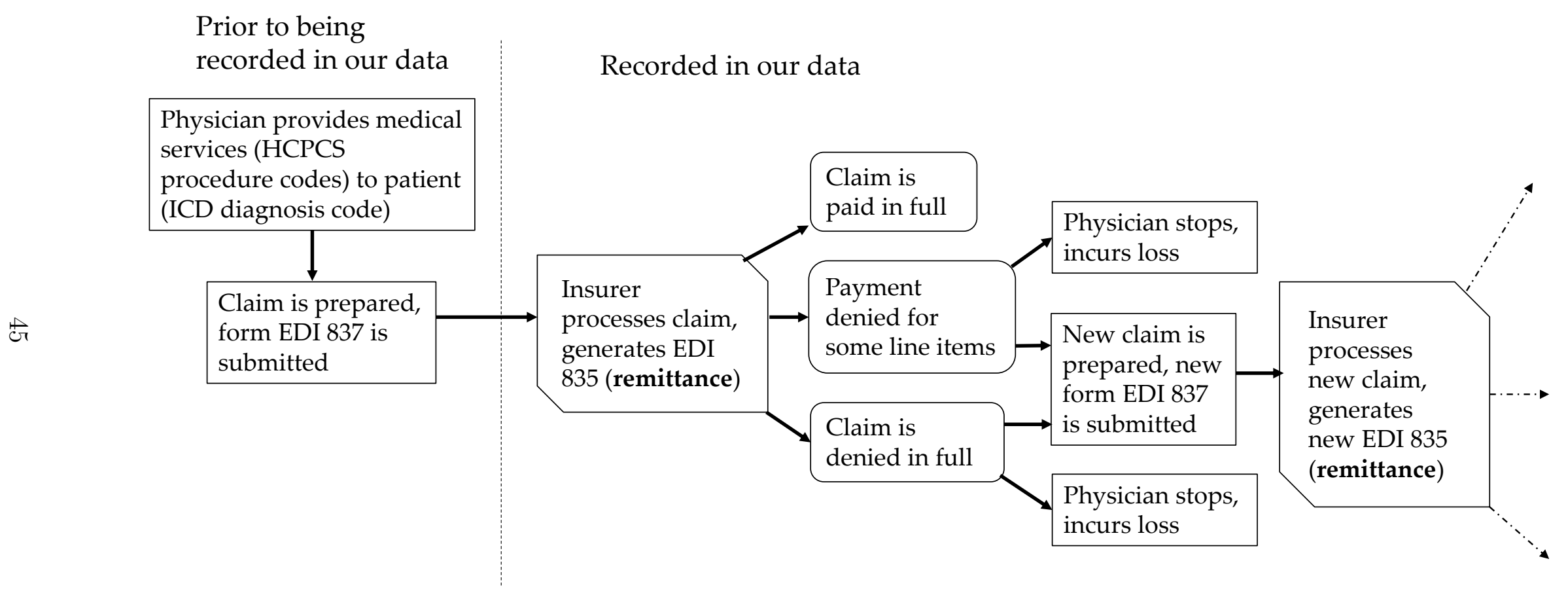

Note: This figure represents a schematic overview of the billing processes following a visit. The vertical dashed line separates the part of the process that is not observed (on the left) from the part observed in the remittance data (on the right). 
Figure 2: Variation in Visit Amounts, Denials, and Resubmissions

(a) Medicaid, Amounts and Denials

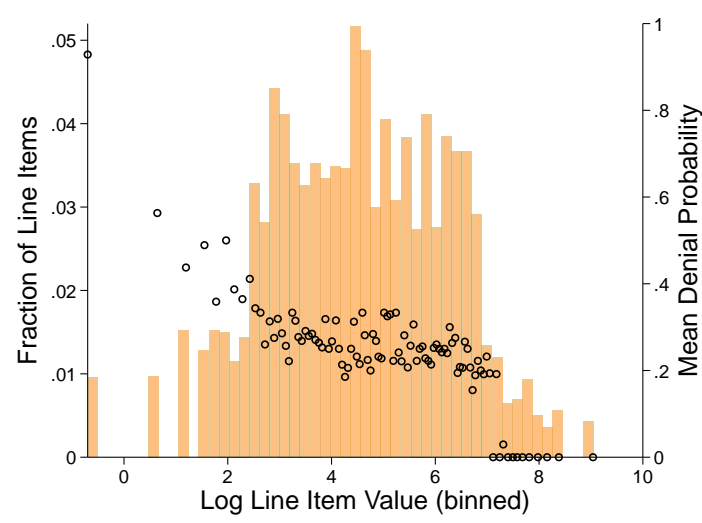

(c) Medicare, Amounts and Denials

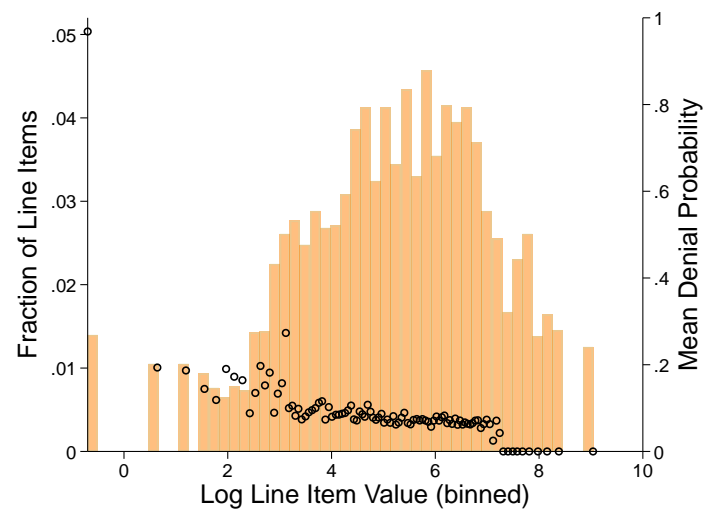

(e) Comm., Amounts and Denials

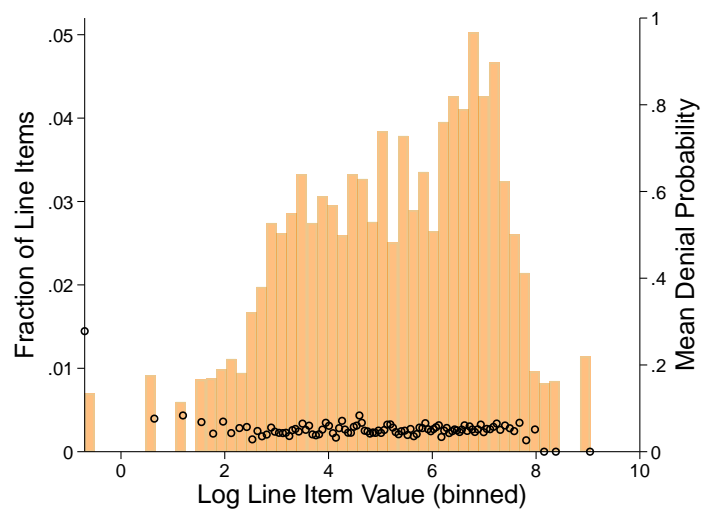

(b) Medicaid, Amounts and Resubmissions

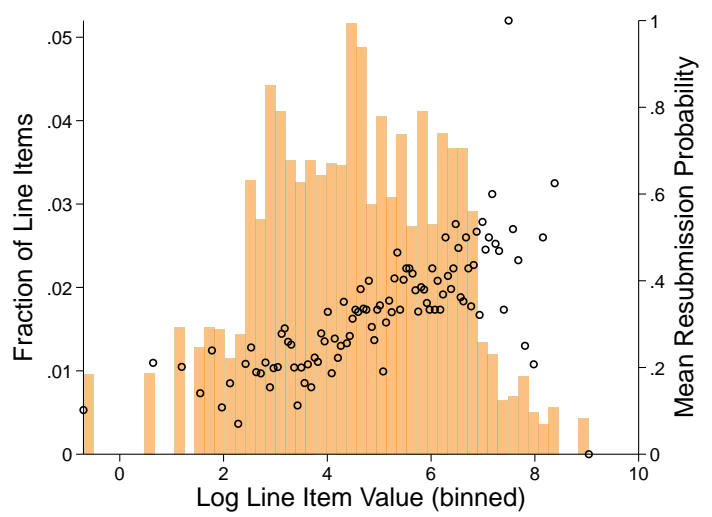

(d) Medicare, Amounts and Resubmissions

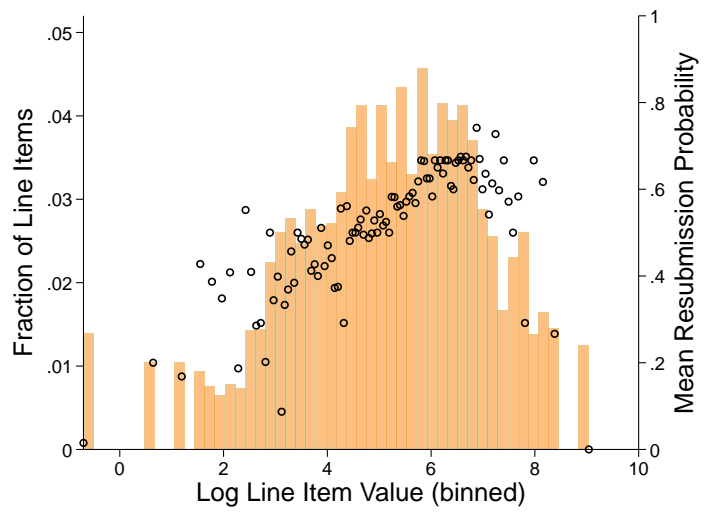

(f) Comm., Amounts and Resubmissions

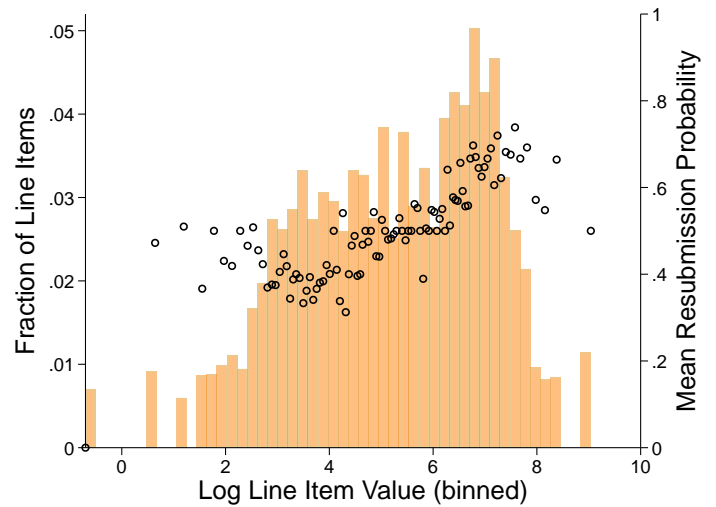

Note: For each payer, this figure overlays a histogram of the initial claim values at the visit level (values can be read on the left vertical axis) with a binscatter plot of the probability of denial (Panels (a), (c) and (e)) and a binscatter plot of the probability that a denied item is resubmitted (Panels (b), (d) and (f)). 
Figure 3: Probability of Resubmission and Continuation Value

(a) Conditional on Payer

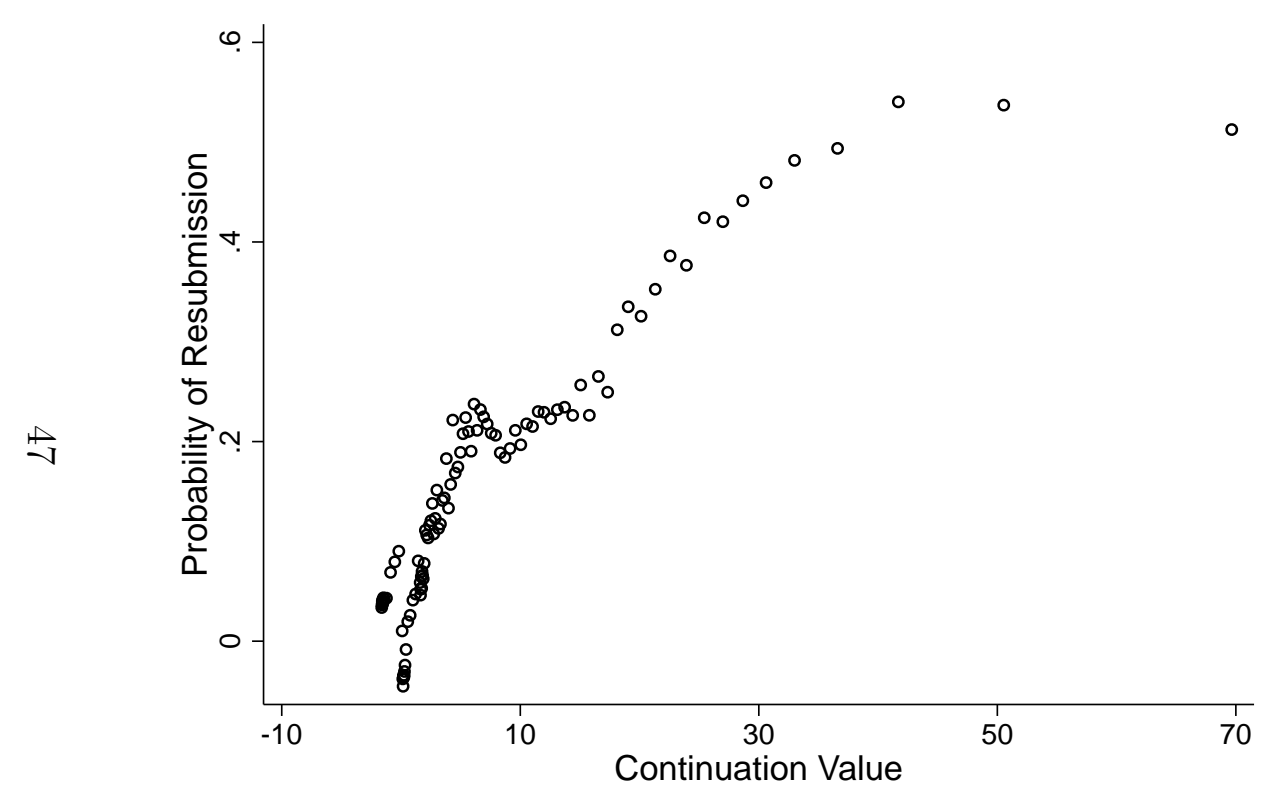

(b) Conditional on Payer and Diagnosis

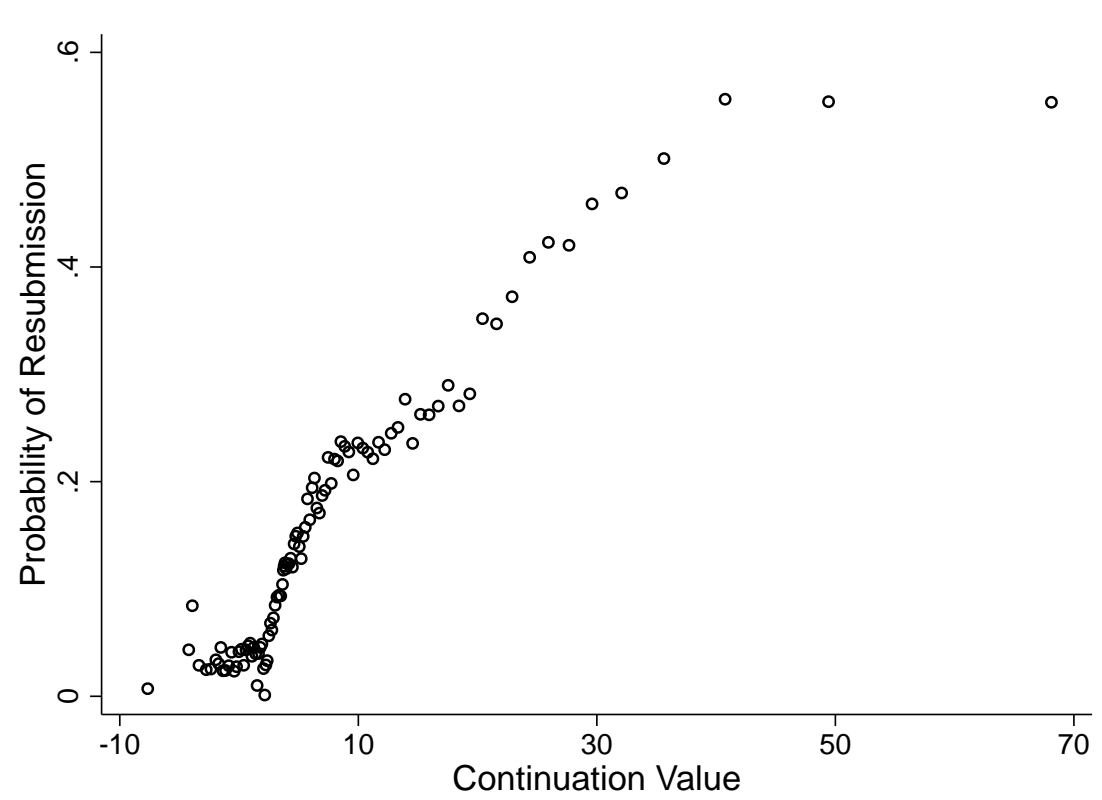

Note: This figure shows a binscatter of the probability that a set of line items is resubmitted (vertical axis) plotted against the continuation value estimated with the remittance data, accounting for future payments, denials, and the probability of submitting further claims. Panel (a) is plotted conditional on payer, and Panel (b) conditional on payer and diagnosis (ICD) code. 
Figure 4: Estimates of Resubmission Costs

(a) Medicaid

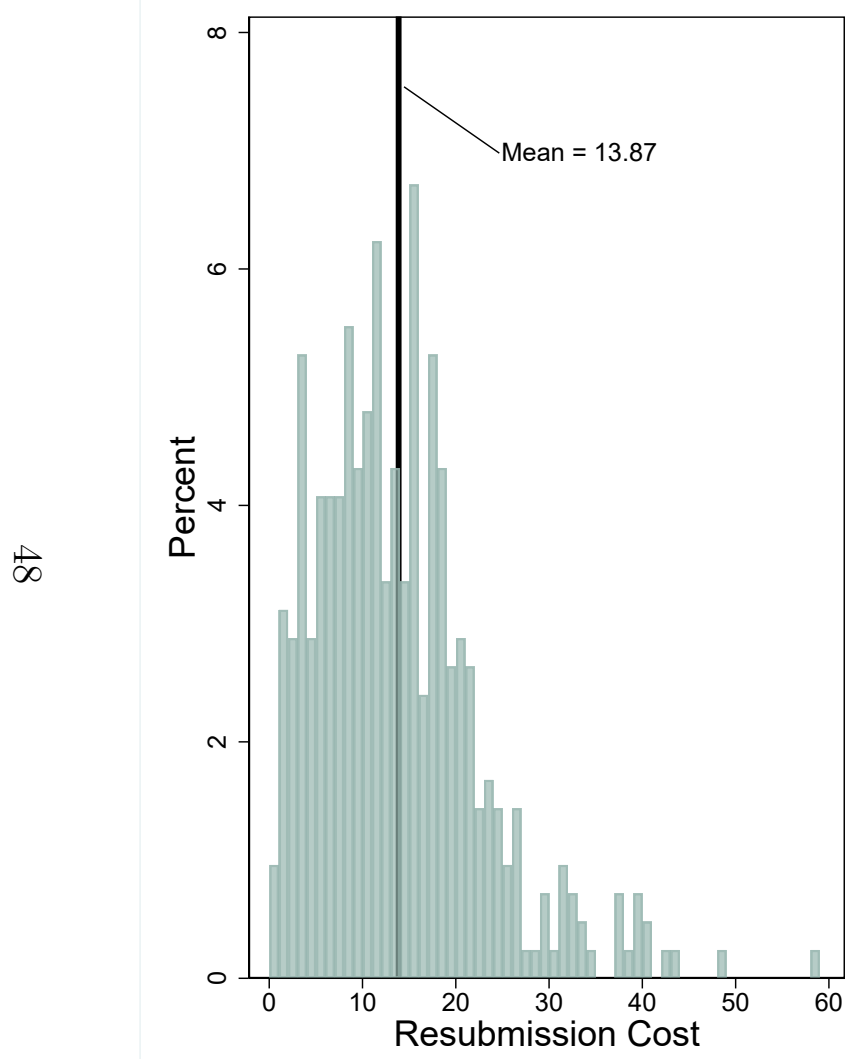

(b) Medicare

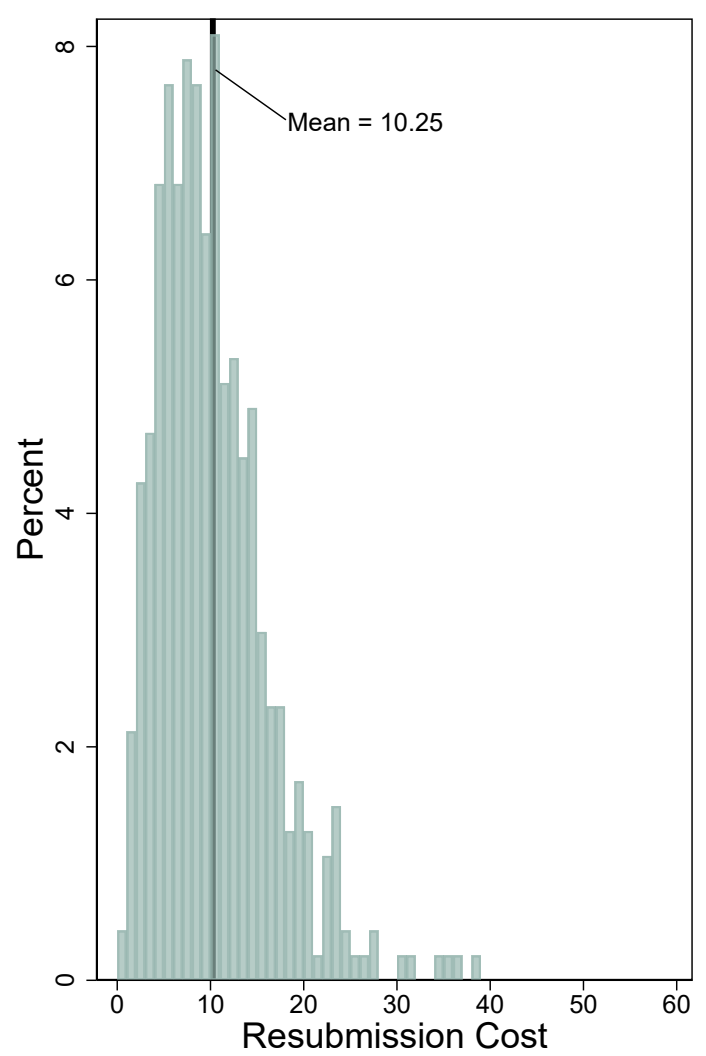

(c) Commercial

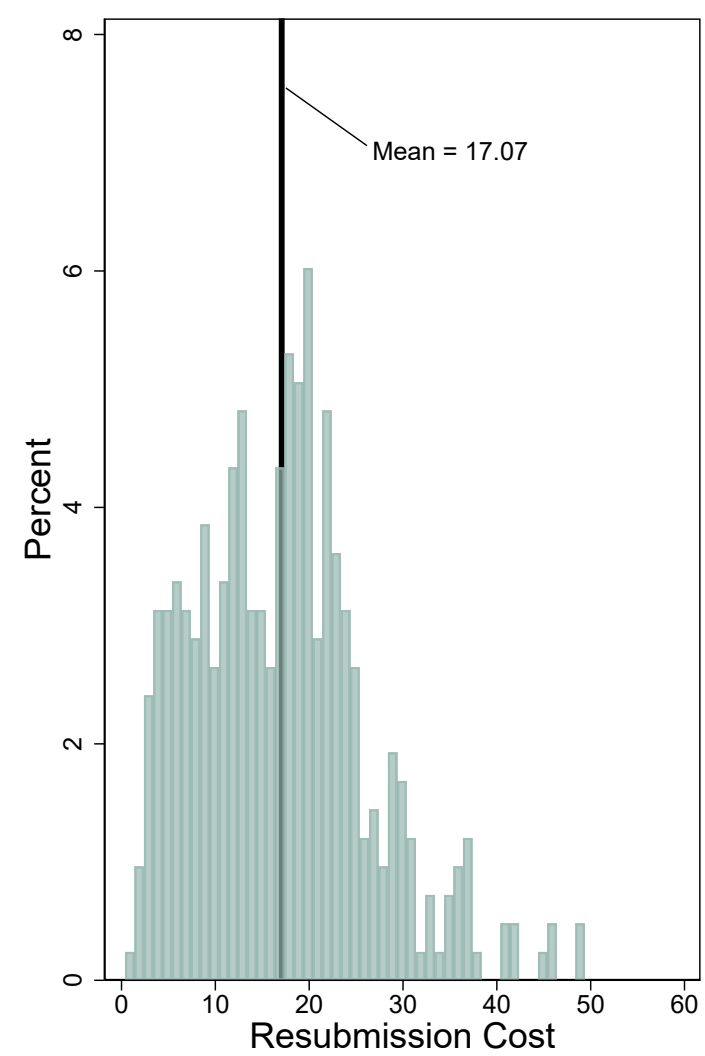

Note: This figure contains histograms of the estimated resubmission costs (for visit with one line item) varying across state, reason code, and size of physician practice. Each panel corresponds to a payer, and the vertical black line denotes the mean resubmission cost. 


\section{Figure 5: Costs of Incomplete Payments Estimated Across States and Payers}

(a) Medicaid, CIP

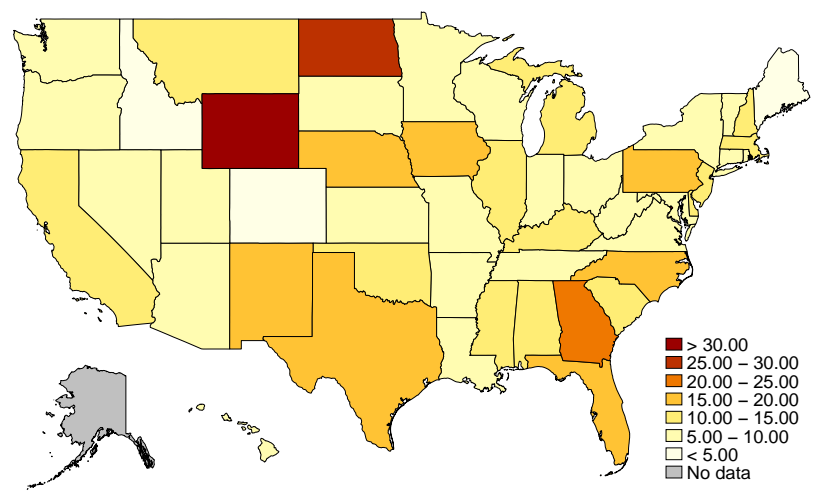

(c) Medicare, CIP

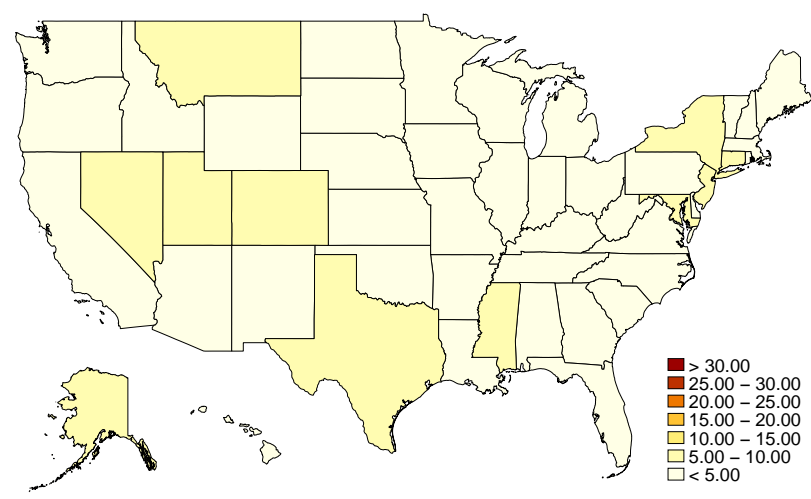

(e) Commercial, CIP

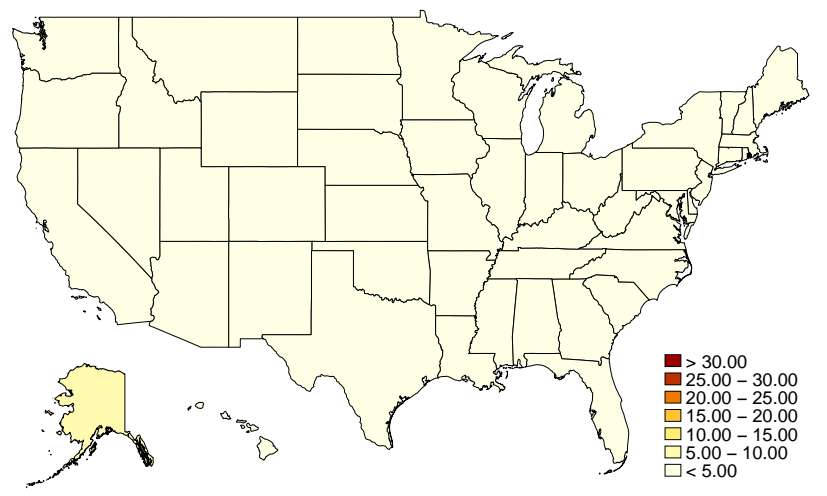

(b) Medicaid, $\tau$

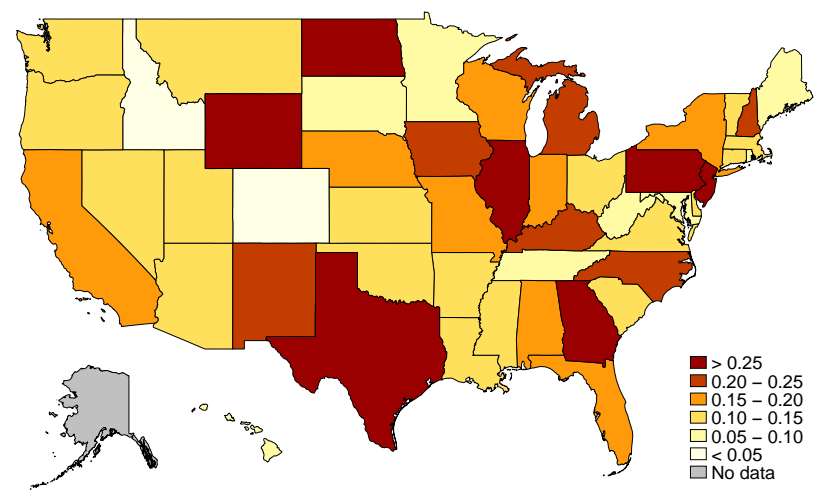

(d) Medicare, $\tau$

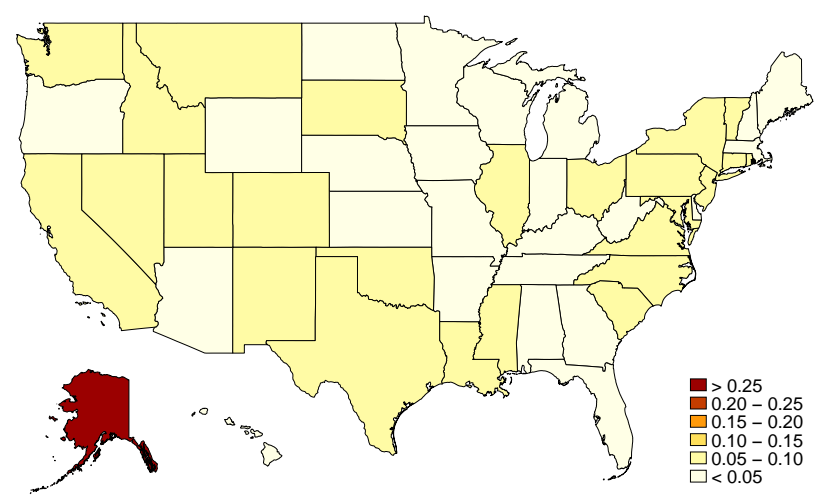

(f) Commercial, $\tau$

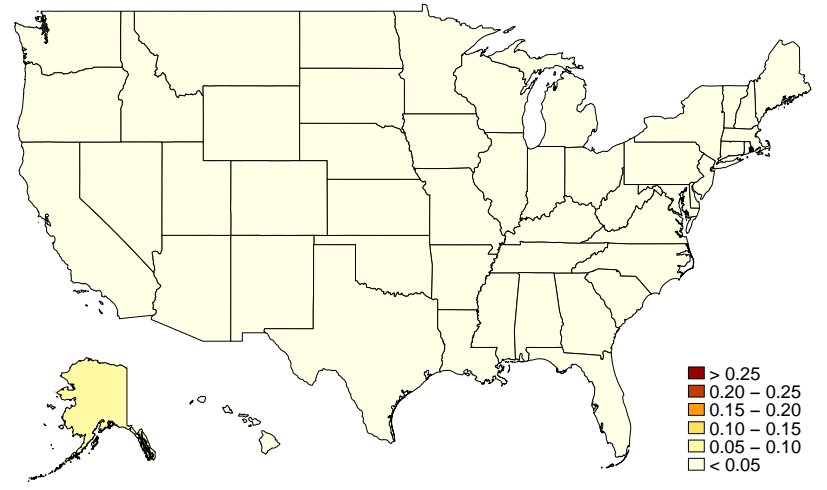

Note: The left column shows the mean estimated costs of incomplete payments (CIP) by state and payer. The right column shows the mean CIP as a share of visit value by state and payer. For each state and payer, we compute the average across observed visits using the estimates corresponding to columns (4) and (5) in Table 5. 
Figure 6: $\log (\pi)$ and $\tau$ Indices Across States

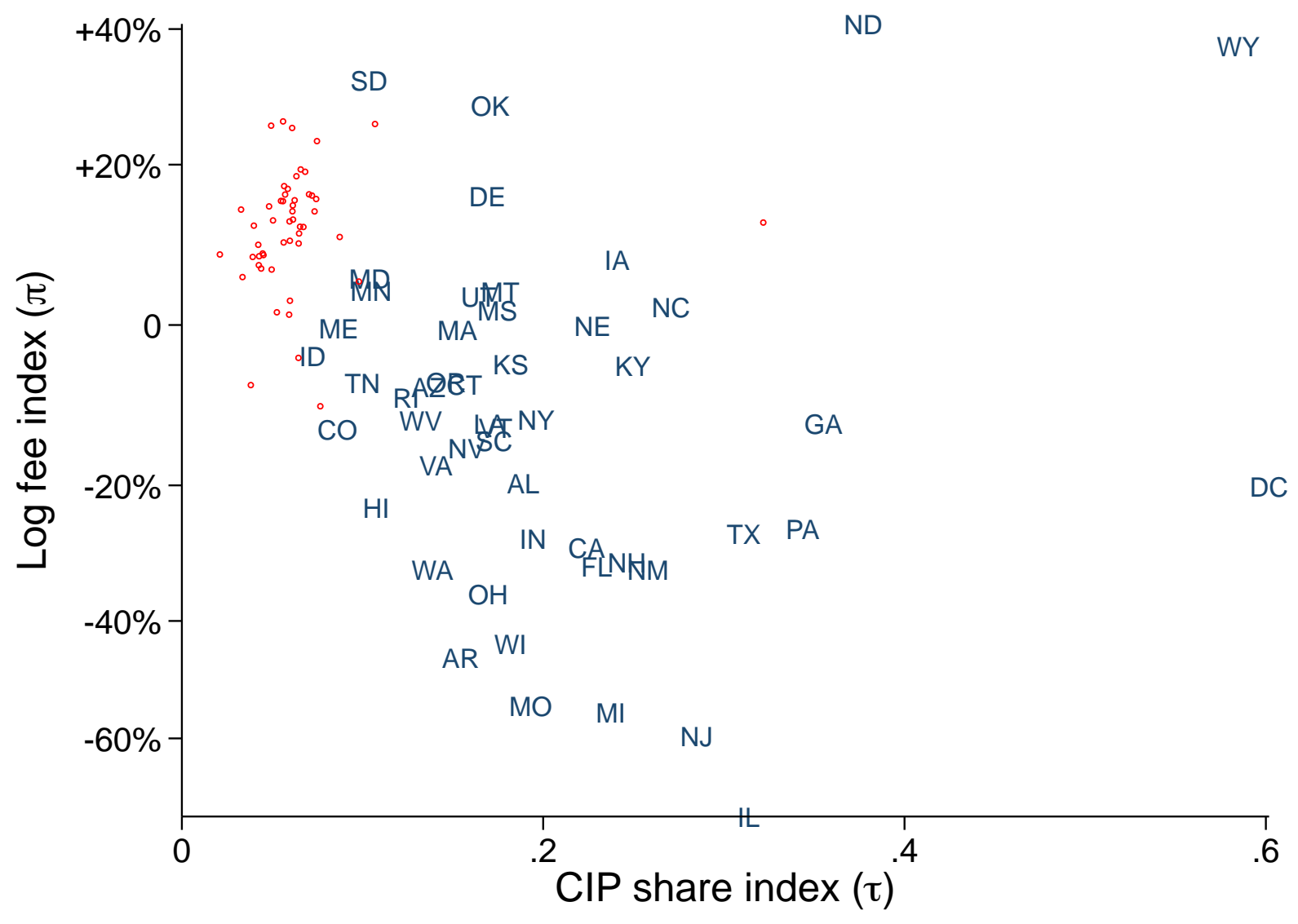

Note: This figure plots the indices for $\log (\pi)$ and $\tau$ estimated in equations (5) and (6), including the selection correction described in footnote 28. The red dots correspond to Medicare indices, one for every state. Medicaid indices are plotted using each state's postal abbreviation. 
Figure 7: Event Study Graphs: Estimates from Equation (12)

(a) $\beta_{\zeta}:$ Effect of $\ln \pi$

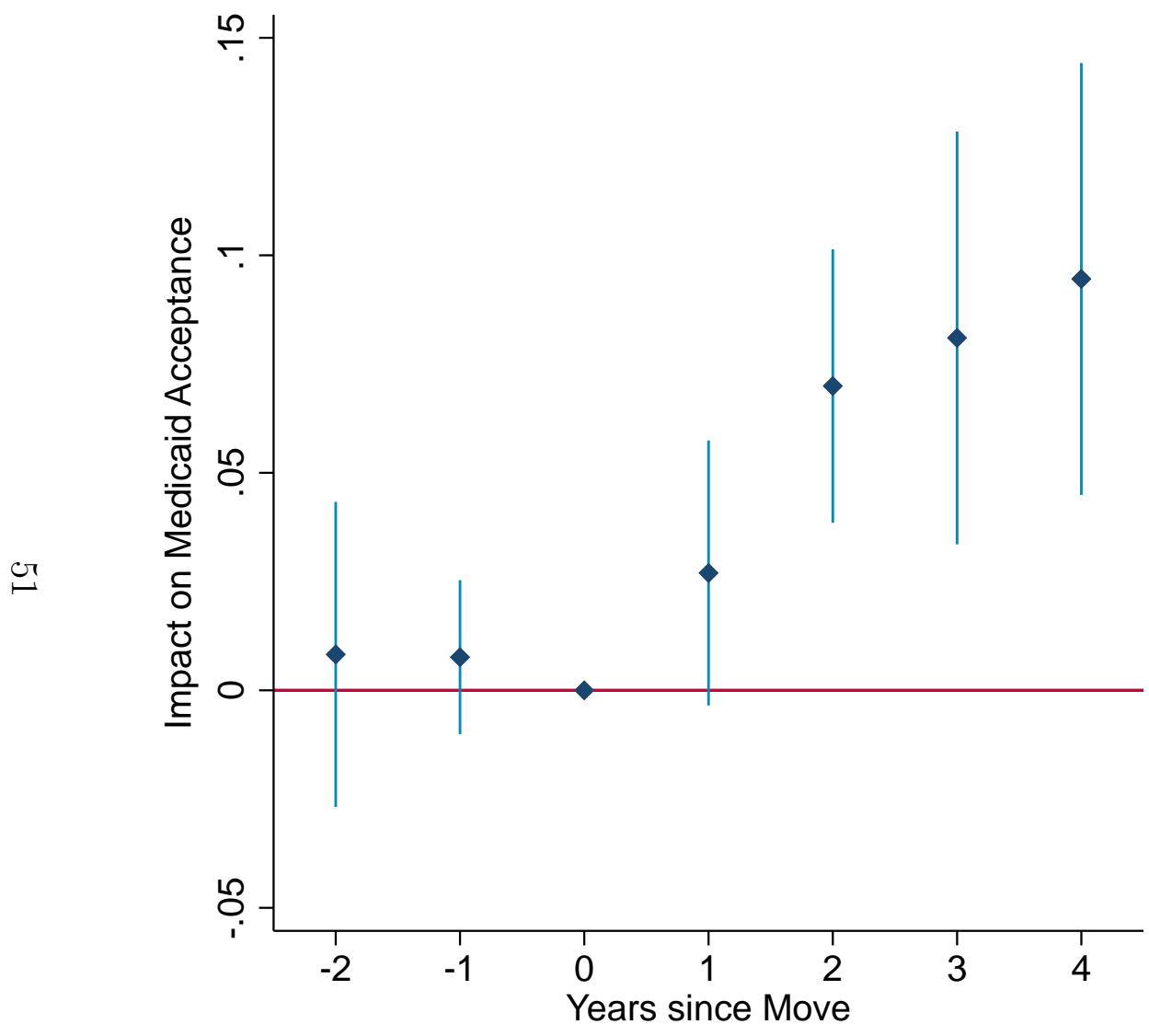

(b) $\gamma_{\zeta}:$ Effect of $\tau$

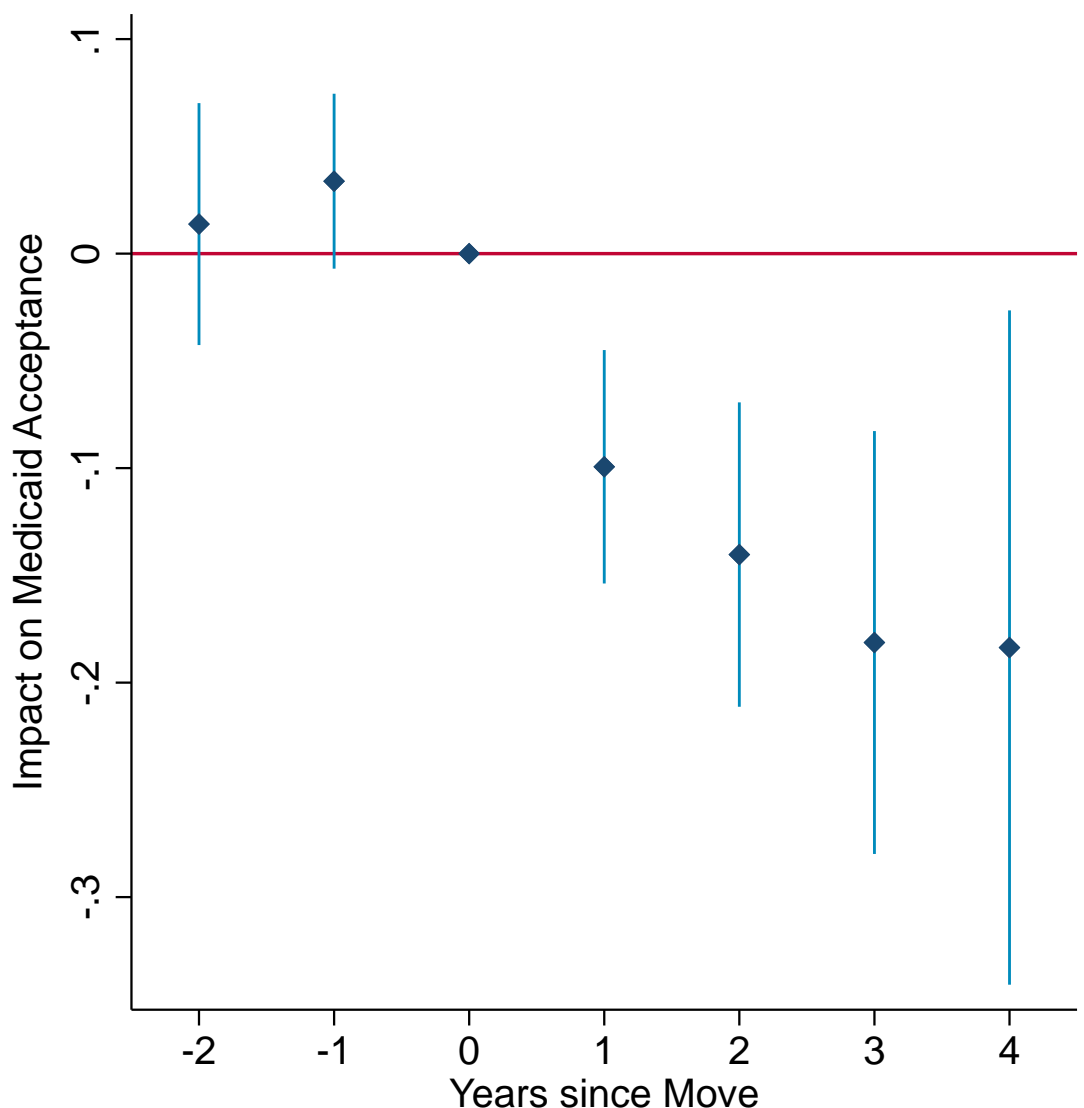

Note: This figure plots the coefficients of the movers event study $\hat{\beta}_{\zeta}$ and $\hat{\gamma}_{\zeta}$ from estimating equation (12). Each observation in the underlying regression is a physician-year, including only physicians moving across states, from 2 years before the move through 4 years after. Panel (a) shows the coefficients $\hat{\beta}_{\zeta}$, capturing the effect of the fee index on the probability physicians accept Medicaid patients. Panel (b) shows the coefficients $\hat{\gamma}_{\zeta}$, capturing the effect of $\tau$ on the same probability. In both panels, the horizontal axis $\zeta$ indicates the year relative to the physician's move. Standard errors are clustered at the state level. 
Figure 8: Policy Counterfactuals Varying Fees and Denials

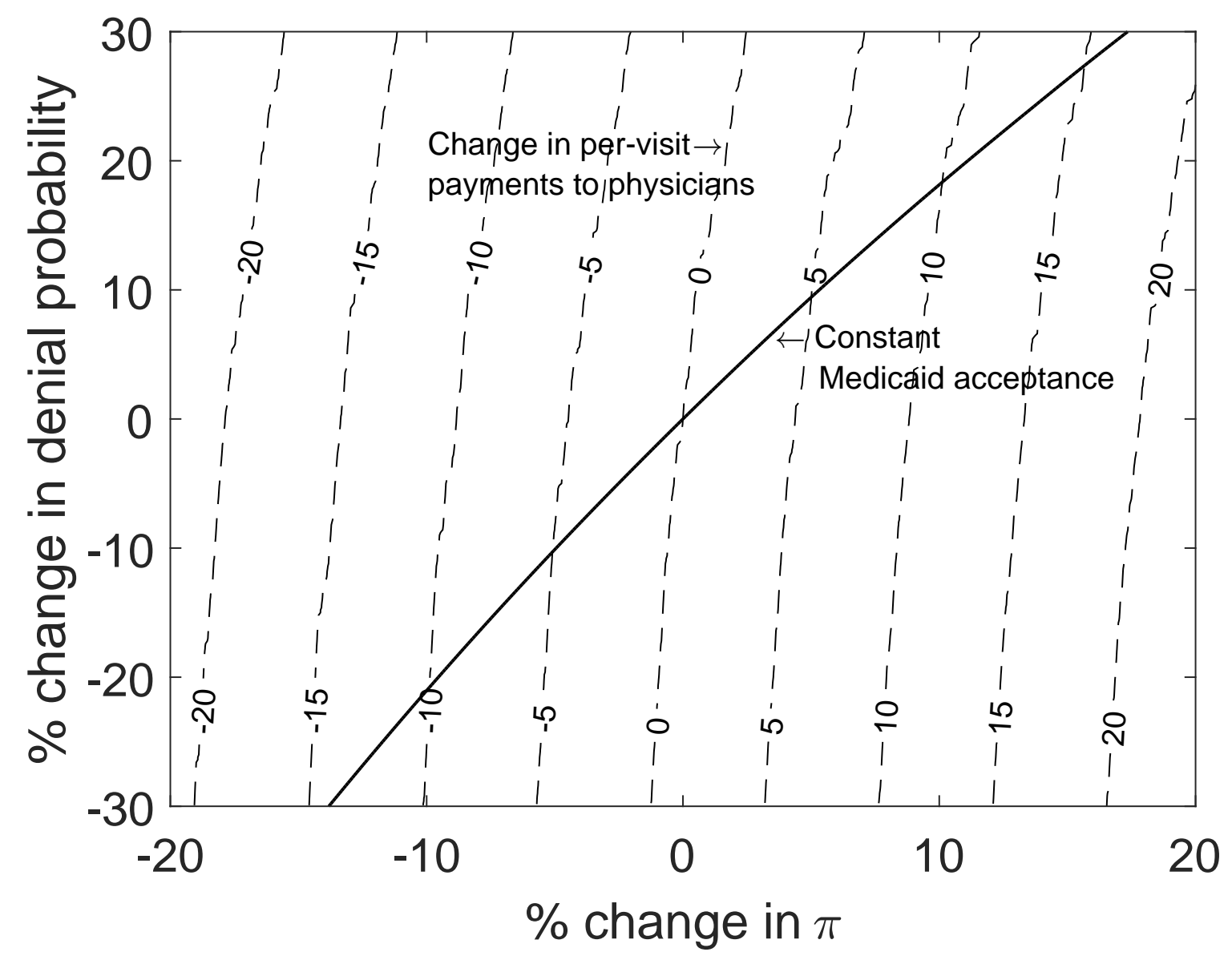

Note: This figure shows how percentage changes in fees and denial probabilities affect Medicaid acceptance and per-visit payments to physicians. The origin for both axes is normalized to the observed level in the data. Values on the horizontal axis correspond to a percentage change in $\pi$, and values on the vertical axis a percentage change in $d$. For example, a value of +10 on the vertical axis means that we change the distribution $F(\pi, d)$ to $F(\pi, 1.1 d)$. The solid line indicates changes in fees and denial probabilities that keep Medicaid acceptance constant. The dashed lines indicate varying levels of per-visit payments to physicians. 


\section{Appendix}

\section{A Data Construction and Auxiliary Empirical Evidence}

This appendix describes in detail how we transform the original IQVIA dataset into our estimation sample. We also provide empirical evidence supporting the use of the SK\&A survey to measure physicians' willingness to accept patients, and motivating our maintained assumption that physicians do not adjust services to the probability of denials.

\section{A.1 Details of Data Construction}

To convert the original IQVIA data into an analysis dataset, we apply some straightforward pre-processing steps to determine resubmissions of previously submitted claims.

For a single visit, we can observe multiple claims, each with multiple line items. We determine a patient visit based on anonymized physician and patient identifiers and the date of service. For each claim, we observe the date at which the claim was submitted to the insurer by the physician's office, the date at which the insurer paid or declined reimbursement for this claim, and the amount that was authorized in case of approval.

In order to avoid overestimating the ensuing costs of this process, we determine resubmissions by their timeline - so that submissions that were not a response to an insurer's decision are not counted - rather than using claim identifiers provided by IQVIA. In particular, we only count a submission as a resubmission of a previously submitted claim of that visit if the submission in question occurs after a decision about a previous submission has been made by the insurer. By doing this we avoid overestimating the costs of the billing-process due to submissions that were not submitted in response to an insurer's decision.

Finally, we drop Medigap and other secondary insurers, claims with values of $<\$ 0$ or $>\$ 1,000,000$, the bottom and top one percent of line item values within each CPT codeinsurer-year combination, and line items valued at $<\$ 0.01 .^{36}$ To eliminate outliers, we drop visits in the top one percent of CIP values in our model estimation.

Merging Data Sources. Our key data sources - the remittance data, the MD-PPAS physician administrative data, and the SK\&A survey - all provide the physician's National Provider Identifier (NPI). We use this to merge them.

\section{A.2 Inferring the Insurer-Physician Contract}

An inherent challenge in data of this form is that we naturally do not observe the allowed amounts for line items that are denied payment within a claim.

For the line items for which these amounts are not observed, we use a three-step algorithm to impute the contractual amounts that would have been collected by the provider, had the claim been approved and processed smoothly, and fully paid.

\footnotetext{
${ }^{36}$ The step that drops claims valued at $>\$ 1,000,000$ drops 483 observations, representing $\$ 9.754$ billion out of $\$ 131.9$ billion in spending in the raw data. The second step drops the top and bottom 1 percent of line item amounts by procedure code, year and payer. For line items above the 99th percentile, this drops 1,642,260 observation which represent $\$ 692.7$ million in spending. For line items below the first percentile, this drops 1,362,479 observation which represent $\$ 43.2$ million in spending.
} 
Step 1: Whenever possible we impute the contractual amount as the average allowed amount for claims processed smoothly by same insurer, when paying the same physician for the exact same procedure (HCPCS code).

Step 2: When there are no claims available matching the criteria required for step 1, we impute the claim value based on the average markup between the insurer's allowed amounts to the provider and standard fee-for-service Medicare rates across all other HCPCS codes. We compute this markup and then impute the contractual amount to be the fee-for-service Medicare rate for the specific line item, multiplied by this insurer-provider-specific markup.

Step 3: In the few instances in which we lack the data required for either step 1 or 2 , we compute the average discount from the billed charges to the allowed amounts specific to the insurer-provider pair. Then, we impute the contractual amount by applying this insurerphysician-specific discount to the observed billed charges for the specific line item. (This is the one exception mentioned in footnote 8.)

\section{A.3 Medicaid Acceptance: Representativeness and Variation}

The key outcome of our analysis is the probability that a physician accepts patients covered by Medicaid. We observe this variable in a near-universal survey of physicians; however, it is self-reported so potentially imperfect.

In this appendix we compare the distribution of Medicaid acceptance probability across states using the SK\&A survey against the same object directly inferred from the (smaller) IQVIA sample. Figure A.1 shows the state-level correlation. For the vast majority of states, the survey matches very closely the probability of accepting Medicaid observed in the remittance data. ${ }^{37}$

A second possible concern in using survey data is that observed changes in Medicaid acceptance result from changes in measurement rather than behavior. This would be particularly concerning if we observed no variation in behavior in non-moving physicians. Table A.1 shows that this is not the case. Every year, 4.8 percent of physicians who do not move across states switch their decision regarding accepting Medicaid patients. For movers (not surprisingly) this churn is higher, at 8.3 percent.

Our analysis in Section 4 uses two strategies. In one, we treat physicians as the decision maker. In the other, we leverage the fact that the physician's group may have a big influence on Medicaid acceptance decisions. We include both strategies for two reasons: (1) this demonstrates the robustness of our findings to alternative assumptions, and (2) the data provide partial support for both assumptions.

Figure A.2 shows that for over 40 percent of group-year-state observations, there is no variation in Medicaid acceptance within group. For observations with some variation, the standard deviation of acceptance across physicians within the group-state-year is distributed approximately uniformly between 0.1 and 0.5. Figure S.2 in the Supplemental Appendix shows a version of this figure in which each group is weighted by the number of physicians in the group.

\footnotetext{
${ }^{37}$ Some exceptions include California, the District of Columbia, Rhode Island, and Hawaii.
} 


\section{A.4 Billing Hurdles and Intensity of Care}

Our analysis in this article focuses on physicians' extensive margin decisions of whether to accept Medicaid patients. Throughout, we take as given the care that patients receive, assuming physicians' treatment decisions do not respond to billing hurdles. If physicians were to adjust their treatment decisions in response to treatment-specific denial rates, our results would miss a key mechanism through which billing hurdles affect supply of care.

In this appendix we use the richness remittance data to verify that intensive margin adjustments of this sort do not seem to pose a first order concern. In particular, we show that, conditional on a very large set of observables, physicians are not differentially likely to administer a given procedure to patients covered by different payers. Moreover, to the extent that the intensity of care differs across payers, these differences are not correlated with differences in the probability of a denial.

In order to conclude this, we consider the most common one thousand combinations of diagnosis and Charlson severity index; index these by $x$ (not to be confused with $X_{j}$ in the main text). We then consider the twenty most common procedures being administered to each $x$, say $p_{1, x}, p_{2, x}, \ldots, p_{20, x}$. We then estimate the following relationship:

$$
\text { Probability that procedure } p_{k, x} \text { is administered }=\frac{e^{a_{k, x}+b_{x} \mathbb{1}[\text { Medicaid patient }]}}{1+e^{a_{k, x}+b_{x} \mathbb{1}[\text { Medicaid patient }]}} \text {. }
$$

Rather than focusing on parameters, we construct point estimates and confidence intervals for the difference between the probability that a procedure is supplied to Medicaid patients and the probability that the same procedure is supplied to non-Medicaid patients.

In Figure A.3 we explore whether these differences, if any, are significantly different from zero, and whether they correlate with the probability that a claim is denied. This tells us if physicians are systematically deviating from observed care patterns when they treat a Medicaid-insured patient. If there is no difference, then the difference between the likelihood that a procedure is administered for Medicaid and non-Medicaid should equal zero.

Across the 20,000 combinations we consider, in 47 cases we reject the null in favor of higher intensity of care for Medicaid patients. Conversely - and suggesting the importance of further research - in 4,056 cases we reject the null in favor of less intensity of being care provided to this group. Differences in levels are accounted for in our analysis, since we treat payers separately throughout. However, we further assume that the types of visits and the procedures are exogenous to the denial process, and this is testable.

In Table A.2 we regress the difference in the probability that a specific treatment is administered between non-Medicaid and Medicaid on the difference in the probability that a specific procedure is denied. The resulting coefficient is a precisely estimated near-zero effect: a ten percent increase in denial probability (which would be very large) predicts an increase in the probability of a procedure by 0.082 percent. We see this as strong evidence that, at least in our data, once "the patient is in the room" the physician is not substantially affected by within-payer differences in billing hurdles across procedures. 


\section{B Maximum Likelihood Estimation of Resubmission Costs}

In this appendix we provide the details of the empirical model of resubmission decisions and the maximum likelihood estimation of resubmission costs. We also illustrate the corresponding identifying variation.

\section{B.1 Optimal Resubmission Decisions}

After visit $j$ with characteristics $X_{j}$ takes place, the physician $i$ (with characteristics $Z_{i}$ ) submits an initial claim. This action is outside of our model, since the remittance data "begins" with the initial insurer response recorded in the EDI 835 (as Section 2.1 describes). The initial claim consists of the set of line items $L_{j}$ : for every $\ell \in L_{j}$ the physician expects a payment $\pi_{\ell}$, and the total value of the initial claim is $\pi\left(L_{j}\right)=\sum_{\ell \in L_{j}} \pi_{\ell}$.

If the insurer denies the payment for a subset of line items $D_{j} \subset L_{j}$, the denial has an associated reason code $\rho$. If the physician decides to not resubmit a claim, she does not incur any additional cost, but the visit revenue is $\pi\left(L_{j}-D_{j}\right)$ - where the minus sign indicates difference between sets; $L_{j}-D_{j}=L_{j} \cap D_{j}^{\mathrm{c}}$-rather than $\pi\left(L_{j}\right)$; in this case, the realized $\mathrm{CIP}$ is $\pi\left(L_{j}\right)-\pi\left(L_{j}-D_{j}\right)=\pi\left(D_{j}\right)$.

The physician can instead decide to resubmit any subset of the denied items and try to recover the corresponding revenues. Formally, she can choose any $R_{j} \subset D_{j}$, and, after paying the resubmission cost $C_{i j}\left(R_{j}\right)$, continue the process to the next period. The insurer can then accept to pay $\pi\left(R_{j}\right)$, or deny payment for any subset $D_{j}^{\prime} \subset R_{j}$. This process then continues recursively.

Physicians have correct beliefs about the probability

$$
\operatorname{Pr}\left[D_{j}^{\prime} \mid R, X_{j}, Z_{i}, \rho\right]
$$

that a subset $D_{j}^{\prime}$ of line items is denied for any resubmitted set of line items $R \subset D_{j}$. Then, the resubmission decision $R_{j}$ solves

$$
\begin{aligned}
R_{j} & =\underset{R \subset D_{j}}{\arg \max }-C_{i j}(R)+\delta \mathcal{V}\left(R, X_{j}, Z_{i}, \rho\right), \\
\mathcal{V}\left(R, X_{j}, Z_{i}, \rho\right) & =\mathbb{E}\left[\pi\left(R-D^{\prime}\right)+\max _{R^{\prime} \subset D^{\prime}}\left\{-C_{i j}\left(R^{\prime}\right)+\delta \mathcal{V}\left(R^{\prime}, X_{j}, Z_{i}, \rho\right)\right\} \mid R, X_{j}, Z_{i}, \rho\right],
\end{aligned}
$$

where the expectation in (17) is taken with respect to $D^{\prime}$, using the probability in (15).

\section{B.2 Assumptions and Estimation}

We parametrize the resubmission cost as shown in equation (3):

$$
C_{i j}(R)=\mu\left(|R|, X_{j}, Z_{i}, \rho\right)+\varepsilon_{i j}
$$

where, in our most flexible estimation,

$$
\mu\left(|R|, X_{j}, Z_{i}, \rho\right)=\mu_{\text {insurer }_{j}, \text { state }_{j}, \text { practice }_{\text {size }}, \rho}^{0}+\mu_{\text {insurer }_{j}, \text { practice size }_{i}, \rho}^{1} \times|R|,
$$


and $\varepsilon_{i j}$ is an i.i.d. draw from a Type 1 extreme value distribution.

Then, following the well-known results derived in Hotz and Miller (1993), since choosing not to resubmit $R_{j}=\emptyset$ implies null continuation payoff with certainty, the following holds:

$$
\begin{aligned}
\mathcal{V}\left(R, X_{j}, Z_{i}, \rho\right) & =\mathbb{E}\left[\pi\left(R-D^{\prime}\right) \mid R, X_{j}, Z_{i}, \rho\right] \\
& -\mathbb{E}\left[\ln \left(\operatorname{Pr}\left[R^{\prime}=\emptyset \mid D^{\prime}, R, X_{j}, Z_{i}, \rho\right]\right) \mid R, X_{j}, Z_{i}, \rho\right]+\omega
\end{aligned}
$$

where $\omega \approx 0.5772$ is the Euler's constant.

The remittance data presented in Section 2.2 allows us to derive an empirical counterpart for $\mathcal{V}$, denoted $\widehat{\mathcal{V}}$, estimated using the empirical probability of denials after resubmission conditional on $X_{j}, Z_{i}, \rho$. We denote this empirical probability as

$$
\widehat{\operatorname{Pr}}\left[D_{j}^{\prime} \mid R, X_{j}, Z_{i}, \rho\right] .
$$

To limit dimensionality issues, and considering that more than 50 percent of denied claims only contain one line item:

$$
\operatorname{Pr}\left[D_{j}^{\prime} \mid R, X_{j}, Z_{i}, \rho\right]=\prod_{\ell \in D_{j}^{\prime}} \operatorname{Pr}\left[\{\ell\} \mid R, X_{j}, Z_{i}, \rho\right] \times \prod_{\ell \in R-D_{j}^{\prime}}\left(1-\operatorname{Pr}\left[\{\ell\} \mid R, X_{j}, Z_{i}, \rho\right]\right) .
$$

In words, denials are independent across line items within a resubmitted claim, conditional on $X_{j}, Z_{i}, \rho$. Under (IND), we can estimate

$$
\begin{aligned}
& \widehat{\operatorname{Pr}}\left[\{\ell\} \mid R, X_{j}, Z_{i}, \rho\right] \equiv \frac{\sum_{j \ell} \mathbb{1}\left[\ell \in R \cap D_{j}^{\prime}, X_{j}, Z_{i}, \rho\right]}{\sum_{j \ell} \mathbb{1}\left[\ell \in R, X_{j}, Z_{i}, \rho\right]} \text {, and } \\
& \widehat{\operatorname{Pr}}\left[D_{j}^{\prime} \mid R, X_{j}, Z_{i}, \rho\right]=\prod_{\ell \in D_{j}^{\prime}} \widehat{\operatorname{Pr}}\left[\{\ell\} \mid R, X_{j}, Z_{i}, \rho\right] \times \prod_{\ell \in R-D_{j}^{\prime}}\left(1-\widehat{\operatorname{Pr}}\left[\{\ell\} \mid R, X_{j}, Z_{i}, \rho\right]\right) .
\end{aligned}
$$

Assumption (IND) ensures that we observe a sufficiently large number of observations in the denominator of (21). This assumption is only relevant for situations in which more than one line item is denied; in Supplementary Appendix Table S.1 we estimate our model on the subsample of claims for which only one line item was denied, relaxing (IND).

The last assumption that we impose in our baseline specification is also motivated by the need to avoid the curse of dimensionality when estimating

$$
\widehat{\operatorname{Pr}}\left[R^{\prime}=\emptyset \mid D^{\prime}, R, X_{j}, Z_{i}, \rho\right],
$$

which is the last object needed to obtain $\widehat{\mathcal{V}}$. For this we require that, conditional on insurer, state, and reason code, a physician decision to stop the billing process for a given visit $\left(R^{\prime}=\emptyset\right)$ depends only on the number of denied line items and the total denied amount, while it does not depend on more granular visit characteristics such as diagnosis and primary procedure.

Formally, letting $\widetilde{X}_{j}$ collect insurer, state, and reason code, we simplify estimation by 
assuming that

$$
\operatorname{Pr}\left[R^{\prime}=\emptyset \mid D^{\prime}, R, X_{j}, Z_{i}, \rho\right]=\operatorname{Pr}\left[R^{\prime}=\emptyset|| D^{\prime}\left|, \pi\left(D^{\prime}\right),\right| R^{\prime} \mid, \pi\left(R^{\prime}\right), \widetilde{X}_{j}, Z_{i}, \rho\right] .
$$

We can then compute the empirical analogue $\widehat{\operatorname{Pr}}\left[R^{\prime}=\emptyset \mid D^{\prime}, R, X_{j}, Z_{i}, \rho\right]$ as we did for the denial probabilities in (21).

As with assumption (IND), we impose (SUF) to limit noise in estimating the probability physicians stop the billing process, deciding to not incur additional billing costs and to not recover any further revenues from the visit. However, this assumption is not required, and results in Supplementary Appendix Table S.2 show that our estimates of resubmission costs are robust to relaxing (SUF), estimating $\operatorname{Pr}\left[R^{\prime}=\emptyset \mid D^{\prime}, R, X_{j}, Z_{i}, \rho\right]$ conditional on diagnosis and primary procedure of the visit $j$, in addition to $\widetilde{X}_{j}$.

Equipped with the estimates of $\widehat{\operatorname{Pr}}\left[R^{\prime}=\emptyset \mid D^{\prime}, R, X_{j}, Z_{i}, \rho\right]$ and $\widehat{\operatorname{Pr}}\left[D_{j}^{\prime} \mid R, X_{j}, Z_{i}, \rho\right]$ we

can compute $\widehat{\mathcal{V}}$, and express the probability of observing the resubmission decision $R_{j}$ as a function of the parameters $\boldsymbol{\mu}=\left(\boldsymbol{\mu}^{0}, \boldsymbol{\mu}^{1}\right)$, the resubmission cost parameters which are the target of our estimation (equation (19)). We then obtain the maximum-likelihood estimates of these parameters by solving

$$
\max _{\boldsymbol{\mu}^{0}, \boldsymbol{\mu}^{1}} \prod_{j} \frac{\exp \left[-\mu\left(\left|R_{j}\right|, X_{j}, Z_{i}, \rho\right)+\delta \widehat{\mathcal{V}}\left(R_{j}, X_{j}, Z_{i}, \rho\right)\right]}{\sum_{R^{\prime} \subset D_{j}} \exp \left[-\mu\left(\left|R^{\prime}\right|, X_{j}, Z_{i}, \rho\right)+\delta \widehat{\mathcal{V}}\left(R^{\prime}, X_{j}, Z_{i}, \rho\right)\right]}
$$

This procedure selects the resubmission cost parameters that maximize the probability to observe the resubmission decisions in the remittance data as the solution of the optimal resubmission problem described in Section B.1.

\section{B.3 Identifying Variation}

Table A.3 adds to Figure 3 in the main text to illustrate the variation leading to our estimates of resubmission costs, highlighting differences across insurers. In the top panel of Table A.3, we compare the maximum continuation value from resubmission of a claim between instances in which we observe a resubmission and instances in which we do not. The maximum is taken over all possible resubmission decisions available to the provider (combinations of denied line items).

When providers forego future visit revenues by deciding not to resubmit a claim, we estimate that the maximum continuation value from resubmitting averages $\$ 9.53$ in Medicaid, $\$ 10.91$ in Medicare, and $\$ 10.26$ in commercial insurance. Intuitively, providers' administrative costs for resubmitting claims must be higher than these amounts. When providers decide to resubmit, we estimate that the maximum continuation value from resubmitting would be $\$ 20.14$ in Medicaid, $\$ 18.65$ in Medicare, and $\$ 32$ in commercial insurance. Administrative costs for resubmitting a claim must be, on average, lower than these amounts.

Finally, the difference in resubmission costs for alternative sets of resubmitted line items is identified by comparing the estimated continuation value of the chosen options to the alternatives. The bottom panel of Table A.3 focuses on instances in which we do observe a 
resubmission. It shows that the continuation values for the set of line items the physician resubmits are significantly higher than for the non-chosen alternatives. 
Table A.1: Changes in Medicaid Acceptance: Move and Non-Move Years

\begin{tabular}{lccc}
\hline & $\begin{array}{c}\text { Fraction with } \\
\text { no Change }\end{array}$ & $\begin{array}{c}\text { Fraction Switching to } \\
\text { Accept Medicaid }\end{array}$ & $\begin{array}{c}\text { Fraction Switching to not } \\
\text { Accept Medicaid }\end{array}$ \\
\hline Move Year & 0.917 & 0.040 & 0.043 \\
Non-Move Year & 0.952 & 0.024 & 0.024 \\
\hline
\end{tabular}

Note: This table compares one-year changes in Medicaid acceptance between moving and nonmoving physicians. 
Table A.2: Correlation between $\Delta \mathrm{P}($ administered $)$ and $\Delta \mathrm{P}($ denial $)$

\begin{tabular}{lc}
\hline & $\Delta \mathrm{P}($ administered $)$ \\
\hline$\Delta$ Denial Probability & $0.0082^{* * *}$ \\
& $(0.0010)$ \\
\hline$N$ & 19529 \\
$R^{2}$ & 0.00367 \\
\hline
\end{tabular}

Note: This table shows the OLS regression coefficient corresponding to the right panel of Figure A.3. The dependent variable is the estimated difference between the probability of the procedure conditional on diagnosis-severity in Medicaid relative to Medicare and commercial insurance. The independent variable is the difference in the denial probability between Medicaid vs. Medicare or commercial insurance. 
Table A.3: Continuation Values and Resubmission Decisions

\begin{tabular}{cccc}
\hline & Medicaid & Medicare & Commercial \\
\hline Panel a: Maximum Continuation & Value of Claims & \\
Instances in which providers do not resubmit claims & 9.53 & 10.91 & 10.26 \\
Instances in which providers resubmit claims & 20.14 & 18.65 & 32.00 \\
Panel b: Continuation Value of Resubmission & \\
Not resubmitted set of line items & 5.65 & 7.63 & 9.44 \\
Resubmitted set of line items & 19.09 & 17.59 & 30.71 \\
\hline
\end{tabular}

Note: This table summarizes the variation in continuation values from resubmission across observed and counterfactual resubmission decisions. It highlights that the remittance data are consistent with providers being forward-looking and profit-maximizing, and it showcases the variation we leverage to identify resubmission costs. Panel (a) shows the maximum continuation value across all viable resubmission options, which includes the option not to resubmit. That is, Panel (a) compares the maximum continuation value from resubmission between instances in which the provider chooses to resubmit a set of denied line items, and instances in which the provider chooses to forego visit revenues for the denied items. Panel (b) shown the continuation value conditional on instances in which providers resubmit claims. That is, Panel (b) compares the sets of line items that are resubmitted to their feasible alternatives for instances in which a resubmission is observed. 
Table A.4: Estimates of Resubmission Costs, CIP, and $\tau$

\begin{tabular}{|c|c|c|c|c|c|c|c|c|c|c|c|c|c|c|c|}
\hline & \multicolumn{5}{|c|}{ Medicaid } & \multicolumn{5}{|c|}{ Medicare } & \multicolumn{5}{|c|}{ Commercial } \\
\hline & $\begin{array}{c}\text { All } \\
\text { phys. }\end{array}$ & $\begin{array}{c}\text { All } \\
\text { phys. }\end{array}$ & $\begin{array}{c}\text { All } \\
\text { phys. }\end{array}$ & $\begin{array}{l}\text { Small } \\
\text { group. }\end{array}$ & $\begin{array}{l}\text { Large } \\
\text { group. }\end{array}$ & $\begin{array}{c}\text { All } \\
\text { phys. }\end{array}$ & $\begin{array}{c}\text { All } \\
\text { phys. }\end{array}$ & $\begin{array}{c}\text { All } \\
\text { phys. }\end{array}$ & $\begin{array}{l}\text { Small } \\
\text { group }\end{array}$ & $\begin{array}{l}\text { Large } \\
\text { group }\end{array}$ & $\begin{array}{c}\text { All } \\
\text { phys. }\end{array}$ & $\begin{array}{c}\text { All } \\
\text { phys. }\end{array}$ & $\begin{array}{c}\text { All } \\
\text { phys. }\end{array}$ & $\begin{array}{l}\text { Small } \\
\text { group }\end{array}$ & $\begin{array}{l}\text { Large } \\
\text { group }\end{array}$ \\
\hline Average $\tau$ & $\begin{array}{c}0.141 \\
(0.0001)\end{array}$ & $\begin{array}{c}0.174 \\
(0.0001)\end{array}$ & $\begin{array}{c}0.176 \\
(0.0001)\end{array}$ & $\begin{array}{c}0.183 \\
(0.0003)\end{array}$ & $\begin{array}{c}0.174 \\
(0.0002)\end{array}$ & $\begin{array}{c}0.033 \\
(0.0000)\end{array}$ & $\begin{array}{c}0.047 \\
(0.0000)\end{array}$ & $\begin{array}{c}0.047 \\
(0.0000)\end{array}$ & $\begin{array}{c}0.059 \\
(0.0001)\end{array}$ & $\begin{array}{c}0.044 \\
(0.0000)\end{array}$ & $\begin{array}{c}0.019 \\
(0.0000)\end{array}$ & $\begin{array}{c}0.024 \\
(0.0000)\end{array}$ & $\begin{array}{c}0.024 \\
(0.0000)\end{array}$ & $\begin{array}{c}0.031 \\
(0.0001)\end{array}$ & $\begin{array}{c}0.023 \\
(0.0000)\end{array}$ \\
\hline Average CIP & $\begin{array}{c}9.75 \\
(0.011)\end{array}$ & $\begin{array}{c}12.43 \\
(0.012)\end{array}$ & $\begin{array}{l}12.50 \\
(0.012)\end{array}$ & $\begin{array}{l}13.06 \\
(0.024)\end{array}$ & $\begin{array}{l}12.30 \\
(0.014)\end{array}$ & $\begin{array}{c}2.66 \\
(0.003)\end{array}$ & $\begin{array}{c}3.94 \\
(0.003)\end{array}$ & $\begin{array}{c}3.93 \\
(0.003)\end{array}$ & $\begin{array}{c}4.97 \\
(0.007)\end{array}$ & $\begin{array}{c}3.60 \\
(0.004)\end{array}$ & $\begin{array}{c}1.79 \\
(0.002)\end{array}$ & $\begin{array}{c}2.36 \\
(0.003)\end{array}$ & $\begin{array}{c}2.37 \\
(0.003)\end{array}$ & $\begin{array}{c}2.95 \\
(0.006)\end{array}$ & $\begin{array}{c}2.19 \\
(0.003)\end{array}$ \\
\hline$\mu^{0}$, all & 0 & $\begin{array}{c}10.65 \\
(.03)\end{array}$ & & & & 0 & $\begin{array}{l}8.29 \\
(.02)\end{array}$ & & & & 0 & $\begin{array}{l}10.18 \\
(.04)\end{array}$ & & & \\
\hline$\mu^{1}$, all & 0 & $\begin{array}{c}5.95 \\
(0.01)\end{array}$ & & & & 0 & $\begin{array}{c}-0.96 \\
(0.01)\end{array}$ & & & & 0 & $\begin{array}{c}0.54 \\
(0.01)\end{array}$ & & & \\
\hline$\mu^{0}$, Admin. $\rho$ & & & $\begin{array}{c}15.59 \\
(.06)\end{array}$ & $\begin{array}{c}15.28 \\
(.07)\end{array}$ & $\begin{array}{l}15.05 \\
(.05)\end{array}$ & & & $\begin{array}{c}10.03 \\
(.03)\end{array}$ & $\begin{array}{l}8.70 \\
(.04)\end{array}$ & $\begin{array}{c}11.45 \\
(.04)\end{array}$ & & & $\begin{array}{c}18.96 \\
(.07)\end{array}$ & $\begin{array}{c}18.04 \\
(.09)\end{array}$ & $\begin{array}{c}19.32 \\
(.07)\end{array}$ \\
\hline$\mu^{1}$, Admin. $\rho$ & & & $\begin{array}{c}4.84 \\
(0.02)\end{array}$ & $\begin{array}{c}5.28 \\
(0.04)\end{array}$ & $\begin{array}{c}4.63 \\
(0.03)\end{array}$ & & & $\begin{array}{c}6.65 \\
(0.03)\end{array}$ & $\begin{array}{c}4.47 \\
(0.04)\end{array}$ & $\begin{array}{c}7.87 \\
(0.03)\end{array}$ & & & $\begin{array}{l}16.16 \\
(0.05)\end{array}$ & $\begin{array}{l}12.82 \\
(0.10)\end{array}$ & $\begin{array}{l}16.83 \\
(0.05)\end{array}$ \\
\hline$\mu^{0}$, Contr. $\rho$ & & & $\begin{array}{l}8.54 \\
(.03)\end{array}$ & $\begin{array}{l}6.91 \\
(.06)\end{array}$ & $\begin{array}{l}9.52 \\
(.04)\end{array}$ & & & $\begin{array}{l}7.32 \\
(.03)\end{array}$ & $\begin{array}{l}6.37 \\
(.03)\end{array}$ & $\begin{array}{l}7.75 \\
(.03)\end{array}$ & & & $\begin{array}{l}9.15 \\
(.05)\end{array}$ & $\begin{array}{l}7.23 \\
(.04)\end{array}$ & $\begin{array}{l}8.41 \\
(.05)\end{array}$ \\
\hline$\mu^{1}$, Contr. $\rho$ & & & $\begin{array}{c}4.36 \\
(0.01)\end{array}$ & $\begin{array}{c}4.69 \\
(0.02)\end{array}$ & $\begin{array}{c}4.18 \\
(0.02)\end{array}$ & & & $\begin{array}{l}-5.55 \\
(0.02)\end{array}$ & $\begin{array}{l}-2.43 \\
(0.03)\end{array}$ & $\begin{array}{l}-7.08 \\
(0.02)\end{array}$ & & & $\begin{array}{c}3.35 \\
(0.01)\end{array}$ & $\begin{array}{l}-0.27 \\
(0.03)\end{array}$ & $\begin{array}{l}-0.54 \\
(0.02)\end{array}$ \\
\hline$\mu^{0}$, Cov. $\rho$ & & & $\begin{array}{c}13.89 \\
(.05)\end{array}$ & $\begin{array}{c}12.41 \\
(.07)\end{array}$ & $\begin{array}{l}14.25 \\
(.05)\end{array}$ & & & $\begin{array}{l}10.84 \\
(.03)\end{array}$ & $\begin{array}{c}10.90 \\
(.05)\end{array}$ & $\begin{array}{c}12.22 \\
(.03)\end{array}$ & & & $\begin{array}{c}20.98 \\
(.07)\end{array}$ & $\begin{array}{c}20.01 \\
(.1)\end{array}$ & $\begin{array}{c}20.09 \\
(.09)\end{array}$ \\
\hline$\mu^{1}$, Cov. $\rho$ & & & $\begin{array}{l}8.45 \\
(0.03)\end{array}$ & $\begin{array}{l}8.38 \\
(0.05)\end{array}$ & $\begin{array}{c}8.69 \\
(0.03)\end{array}$ & & & $\begin{array}{c}0.42 \\
(0.02)\end{array}$ & $\begin{array}{l}2.67 \\
(0.06)\end{array}$ & $\begin{array}{l}1.01 \\
(0.02)\end{array}$ & & & $\begin{array}{l}-0.28 \\
(0.06)\end{array}$ & $\begin{array}{l}-6.69 \\
(0.17)\end{array}$ & $\begin{array}{l}1.88 \\
(0.07)\end{array}$ \\
\hline$\mu^{0}$, Dup. $\rho$ & & & $\begin{array}{l}20.69 \\
(.07)\end{array}$ & $\begin{array}{c}17.56 \\
(.1)\end{array}$ & $\begin{array}{l}19.33 \\
(.07)\end{array}$ & & & $\begin{array}{l}11.16 \\
(.04)\end{array}$ & $\begin{array}{l}12.39 \\
(.06)\end{array}$ & $\begin{array}{l}11.12 \\
(.05)\end{array}$ & & & $\begin{array}{l}21.78 \\
(.09)\end{array}$ & $\begin{array}{l}19.66 \\
(.11)\end{array}$ & $\begin{array}{c}21.65 \\
(.08)\end{array}$ \\
\hline$\mu^{1}$, Dup. $\rho$ & & & $\begin{array}{c}0.30 \\
(0.08)\end{array}$ & $\begin{array}{c}-0.62 \\
(0.19)\end{array}$ & $\begin{array}{c}1.07 \\
(0.10)\end{array}$ & & & $\begin{array}{c}-0.26 \\
(0.03)\end{array}$ & $\begin{array}{l}-2.57 \\
(0.07)\end{array}$ & $\begin{array}{c}0.15 \\
(0.03)\end{array}$ & & & $\begin{array}{c}9.56 \\
(0.11)\end{array}$ & $\begin{array}{c}6.55 \\
(0.26)\end{array}$ & $\begin{array}{c}9.00 \\
(0.11)\end{array}$ \\
\hline$\mu^{0}$, Info. $\rho$ & & & $\begin{array}{l}13.94 \\
(.06)\end{array}$ & $\begin{array}{c}11.86 \\
(.08)\end{array}$ & $\begin{array}{c}13.85 \\
(.05)\end{array}$ & & & $\begin{array}{l}9.91 \\
(.03)\end{array}$ & $\begin{array}{l}8.22 \\
(.05)\end{array}$ & $\begin{array}{c}11.66 \\
(.04)\end{array}$ & & & $\begin{array}{c}18.08 \\
(.1)\end{array}$ & $\begin{array}{c}16.78 \\
(.11)\end{array}$ & $\begin{array}{c}19.76 \\
(.12)\end{array}$ \\
\hline$\mu^{1}$, Info. $\rho$ & & & $\begin{array}{c}8.03 \\
(0.03)\end{array}$ & $\begin{array}{c}9.19 \\
(0.06)\end{array}$ & $\begin{array}{c}7.60 \\
(0.04)\end{array}$ & & & $\begin{array}{l}-0.22 \\
(0.03)\end{array}$ & $\begin{array}{c}0.79 \\
(0.05)\end{array}$ & $\begin{array}{l}-0.60 \\
(0.04)\end{array}$ & & & $\begin{array}{c}2.53 \\
(0.07)\end{array}$ & $\begin{array}{l}-2.37 \\
(0.15)\end{array}$ & $\begin{array}{c}3.58 \\
(0.08)\end{array}$ \\
\hline Observations & 0 & $2,492,630$ & $2,492,630$ & 697,304 & $1,795,326$ & 0 & $3,097,916$ & $3,097,916$ & 758,398 & $2,339,518$ & 0 & $2,468,014$ & $2,468,014$ & 533,636 & $1,934,378$ \\
\hline Log Likelihood & 0 & $-1,836,620$ & $-1,510,561$ & $-380,366$ & $-1,154,172$ & 0 & $-3,255,214$ & $-3,116,276$ & $-802,555$ & $-2,200,290$ & 0 & $-1,889,432$ & $-1,676,225$ & $-424,229$ & $-1,338,197$ \\
\hline
\end{tabular}

Note: This table summarizes the resubmission cost parameters from equation (19) estimated via maximum likelihood. Each of the three panels corresponds to a different payer. Within each panel, the first model ignores resubmission costs, so $\tau$ and $C I P$ are simply determined by the average lost revenue. The second model ignores reason codes and practice size, and the third model ignores practice size. The fourth model computes estimates for small groups of one or two physicians, while the fifth model corresponds to groups with three or more physicians. Each value shown in the table is the average of parameters across states. Robust standard errors are in parentheses. 
Table A.5: First Stage: Instrumenting for CIP Index with Denial Rate Index

(a) Movers Strategy First Stage

\begin{tabular}{|c|c|c|}
\hline & \multicolumn{2}{|c|}{ Post-move $\times \Delta \tau$ index } \\
\hline & $(1)$ & $(2)$ \\
\hline Post-move $\times \Delta$ denial rate index & $\begin{array}{c}0.9361^{* * *} \\
(0.0227)\end{array}$ & $\begin{array}{c}0.9282^{* * * *} \\
(0.0626)\end{array}$ \\
\hline Post-move $\times \Delta \log \pi$ index & $\begin{array}{c}-0.0307^{* * *} \\
(0.0114)\end{array}$ & $\begin{array}{c}-0.0633^{* * * *} \\
(0.0200)\end{array}$ \\
\hline Subsample Accepting Medicare & Yes & Yes \\
\hline N. Physicians & 8,182 & 8,182 \\
\hline N. Physicians-Years & 47,806 & 47,806 \\
\hline Physician FE & Yes & Yes \\
\hline Controls & Yes & Yes \\
\hline \multicolumn{3}{|l|}{$\tau$ index: } \\
\hline Physician FE & No & No \\
\hline Selection Correction & Yes & Yes \\
\hline
\end{tabular}

(b) Cross-State Groups First Stage

\begin{tabular}{lcc}
\hline & \multicolumn{2}{c}{$\tau$ Index } \\
\cline { 2 - 3 } & $(1)$ & $(2)$ \\
\hline Denial rate index & $0.9273^{* * *}$ & $0.8988^{* * *}$ \\
& $(0.0207)$ & $(0.0519)$ \\
Log $\pi$ index & $-0.0302^{* *}$ & $-0.0472^{* *}$ \\
& $(0.0118)$ & $(0.0195)$ \\
\hline Subsample Accepting Medicare & Yes & Yes \\
N. Physicians & 232,590 & 232,590 \\
N. Physicians-Years & 807,599 & 807,599 \\
Group FE & Yes & Yes \\
Controls & Yes & Yes \\
\hline$\tau$ index: & & Yes \\
\multicolumn{1}{c}{ Physician FE } & No & Yes \\
\hline
\end{tabular}

Note: This table reports the first stages of the the 2SLS estimation used in columns (2) and (4) of Tables 6 and 7 . Panel (a) shows the first stage for the movers specification, corresponding to equation (14). Panel (b) is the analogue for the cross-state group specification. In each panel, column (1) uses the indices incorporating the selection correction, which is the first stage for column (4) of Tables 6 and 7 , respectively. Column (2) uses the indices estimated conditional on physician fixed effects, which is the first stage for column (2) of Tables 6 and 7 , respectively. 
Figure A.1: Surveyed vs. Sampled Medicaid Acceptance

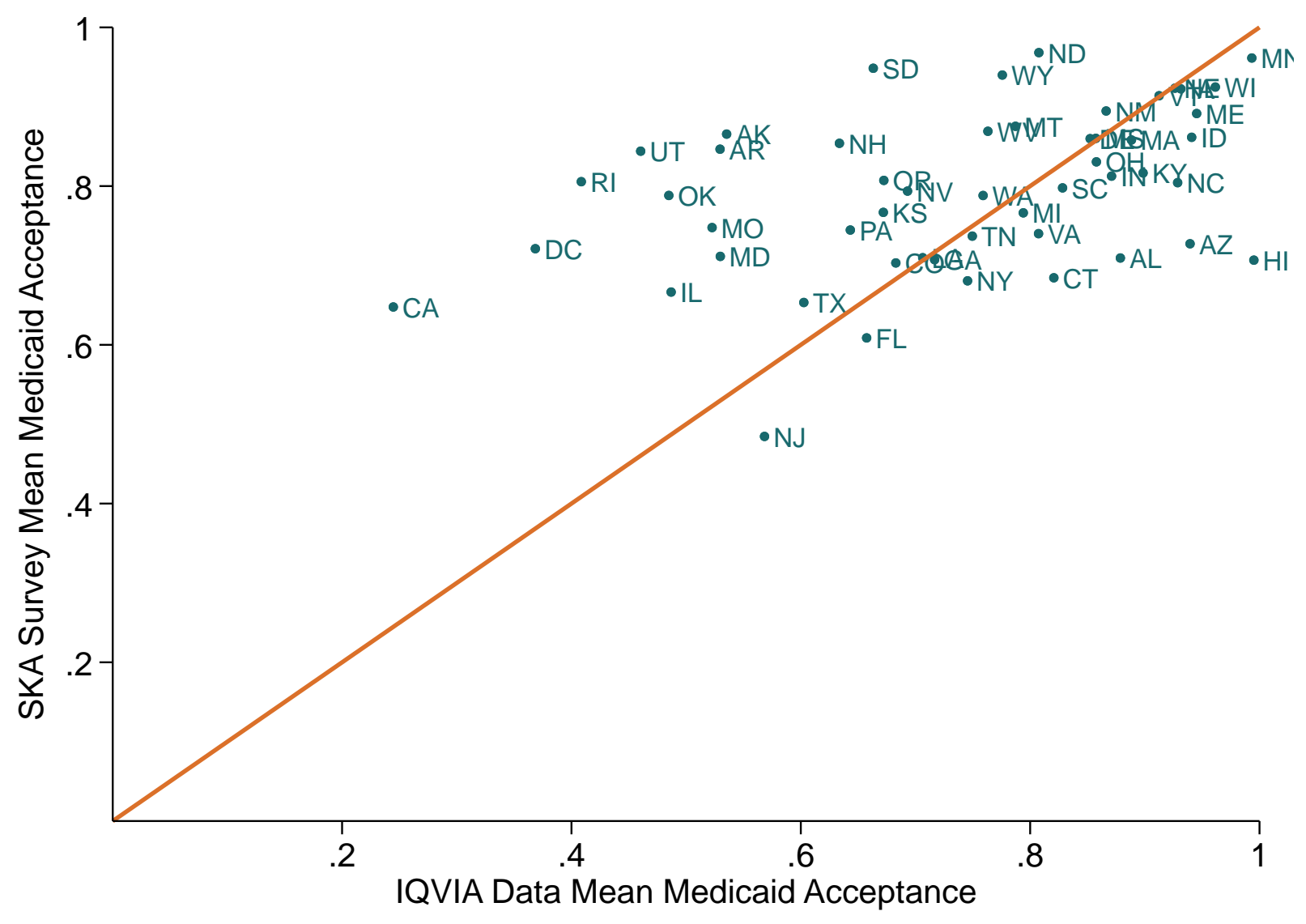

Note: This figure compares the state average Medicaid acceptance measured in the SK\&A survey (vertical axis) to the average Medicaid acceptance in the IQVIA data (horizontal axis). The latter is measured by constructing an indicator for every physician taking value one if we observe at least one Medicaid visit. We then take the average across physicians in the state. 
Figure A.2: Medicaid Acceptance Within Group-Year

(a) All Group-State-Year Observations

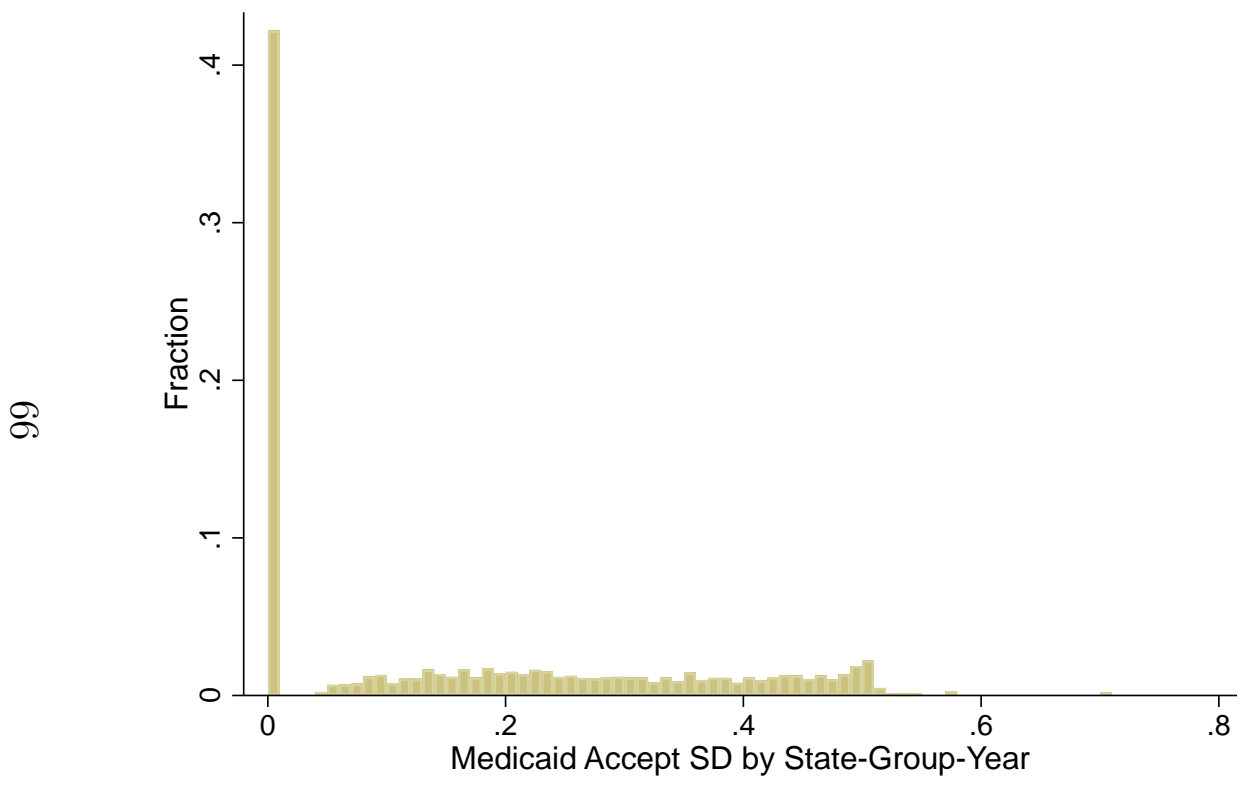

(b) Group-State-Year Observations with $\mathrm{SD}>0$

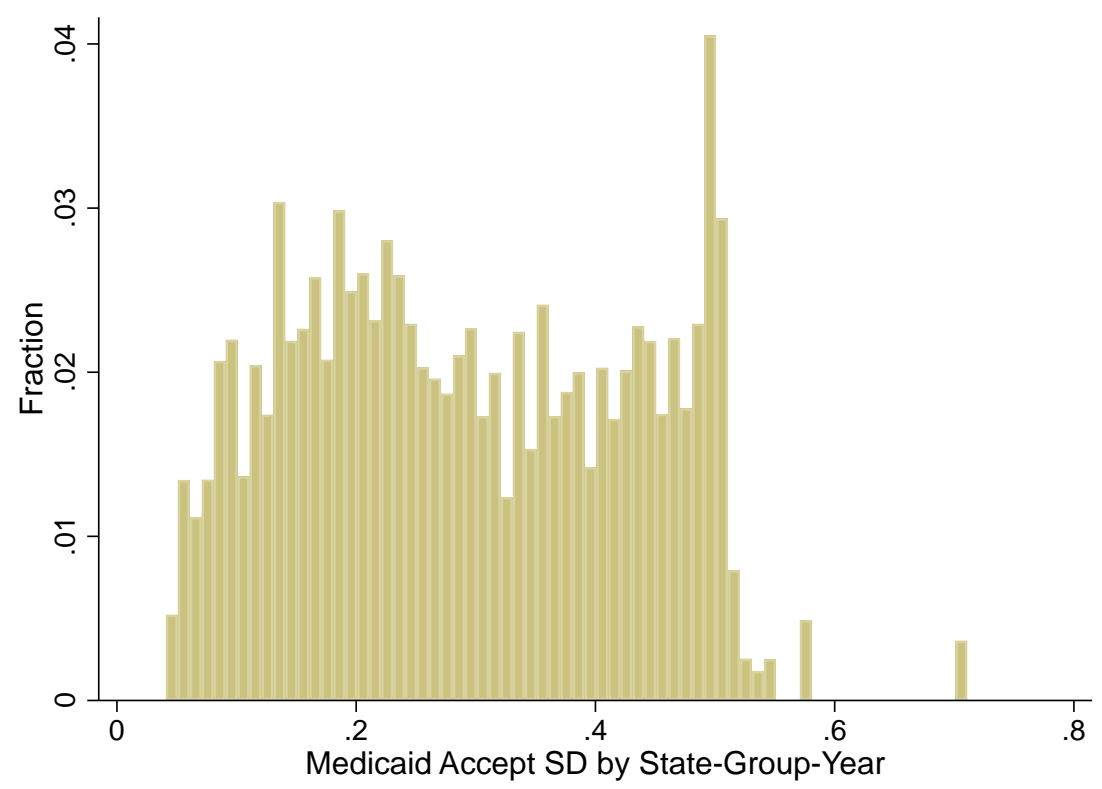

Note: This figure contains histograms of the group-state-level standard deviation of Medicaid acceptance across physicians within the group-state. Panel (a) includes all groups, and Panel (b) includes only groups with variation in Medicaid acceptance within group-state. 
Figure A.3: Variation in Probability of Denial and Probability of a Procedure

(a) Medicaid vs. Denial Probability

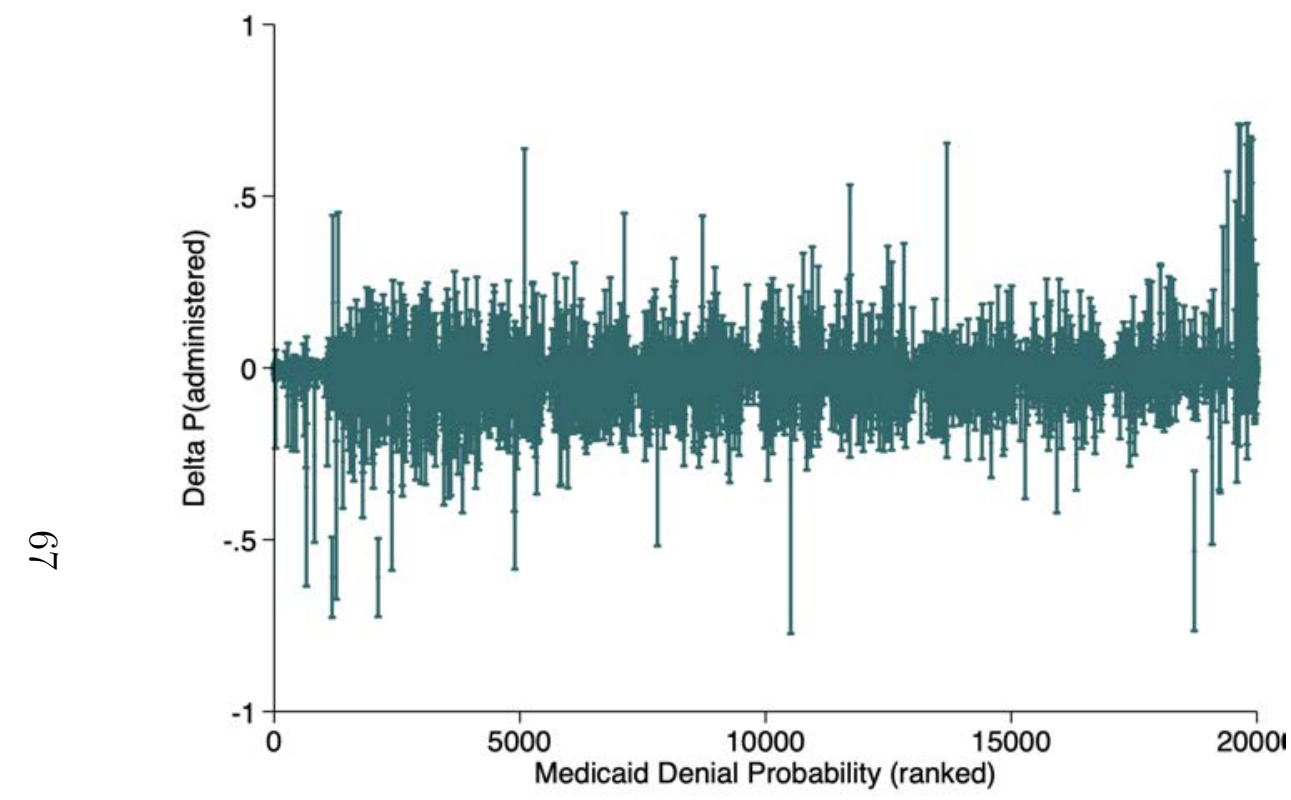

(b) Medicaid vs. Difference in Denial Probability

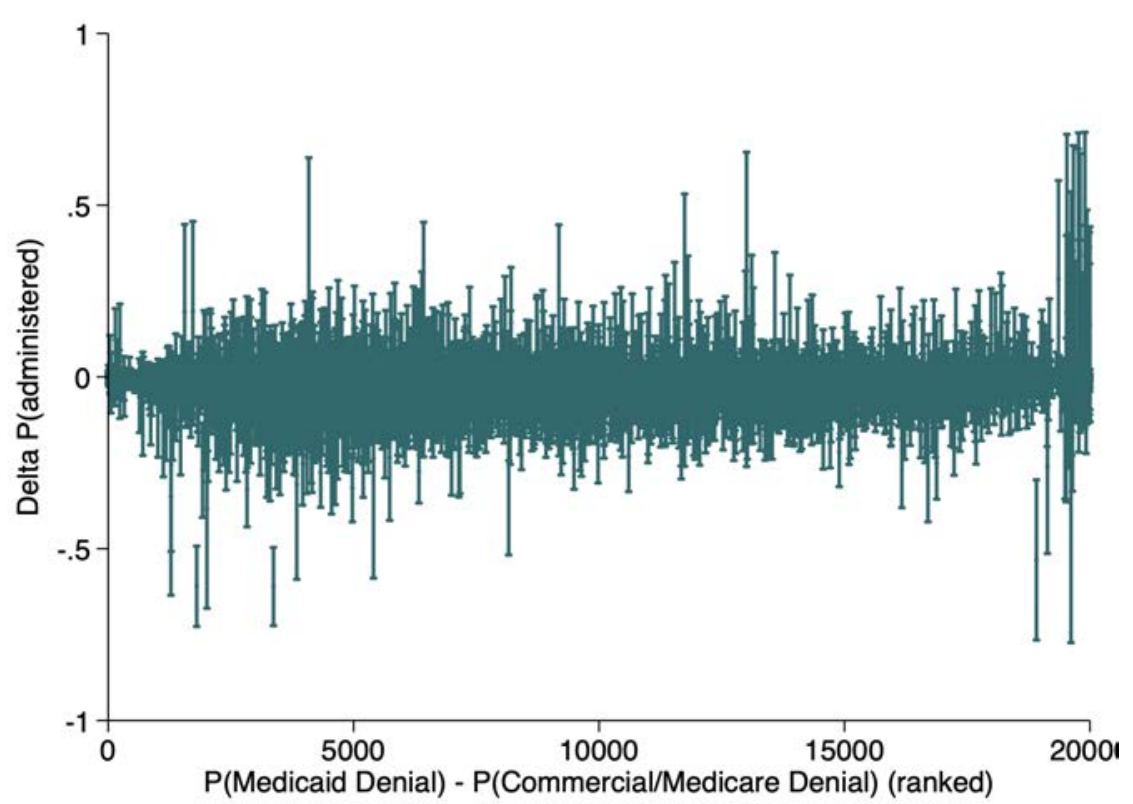

Note: This figure illustrates the relationship between denial probability and difference in the probability of administering a procedure in Medicaid vs. Medicare or Commercial insurance, conditioning on diagnosis and Charlson severity index. In Panel (a), the left axis ranks from 1 to 20,000 the combinations of procedure-diagnosis-severity we consider in Appendix A.4 based on the probability of denial in Medicaid. Each value on the vertical axis (shown along with $95 \%$ confidence intervals) corresponds to the estimated difference between the probability of the procedure conditional on diagnosis-severity in Medicaid relative to Medicare and commercial insurance. In Panel (b) the vertical axis is the same, while the horizontal axis is the (ranked) difference in the probability of denial between Medicaid vs. Medicare or commercial insurance. 